\title{
A CuAAC Click Approach for the Introduction of Bidentate Metal Complexes to a Sulfanilamide-Derived Drug Fragment
}

Reece G. Miller, ${ }^{\dagger}$ Melissa Vázquez-Hernández, ${ }^{\ddagger}$ Pascal Prochnow ${ }^{\ddagger}$ Julia E. Bandow ${ }^{\ddagger}$ and Nils Metzler-Nolte ${ }^{* \dagger}$

†Inorganic Chemistry I - Bioinorganic Chemistry, Faculty of Chemistry and Biochemistry, Ruhr University Bochum, Universitaetsstrasse 150, D-44801, Bochum, Germany. Email: nils.metzler-nolte@ rub.de

${ }^{\ddagger}$ Applied Microbiology, Faculty for Biology and Biotechnology, Ruhr University Bochum, Universitaetsstrasse 150, 44780, Bochum, Germany

\section{Supporting Information}




\section{Table of Contents}

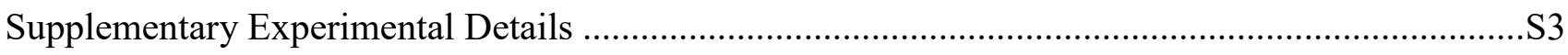

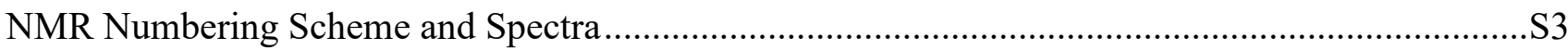

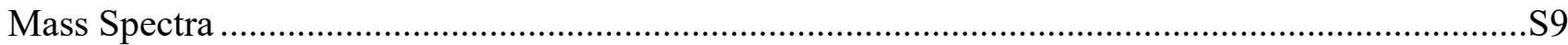

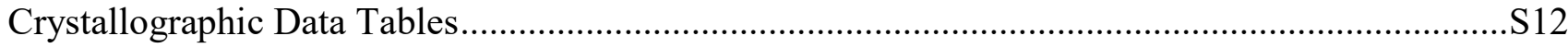

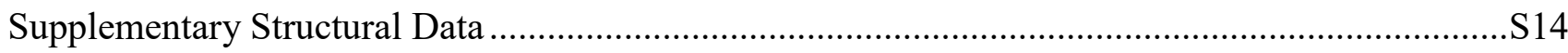

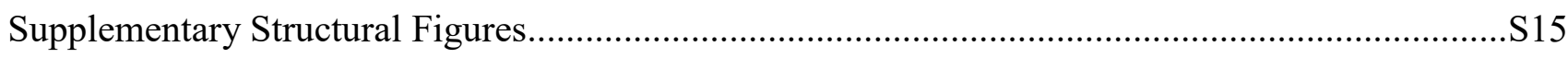

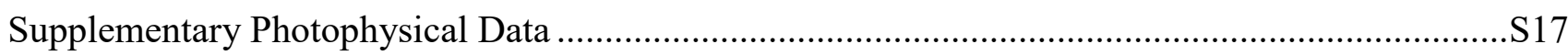

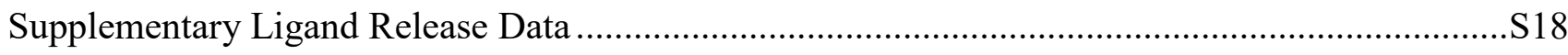

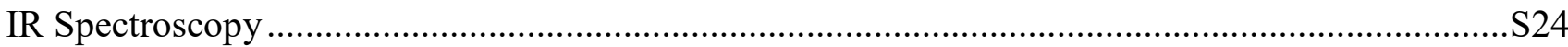

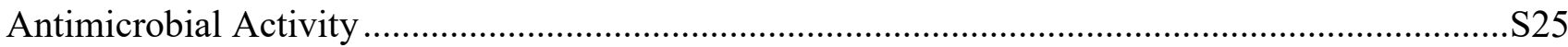

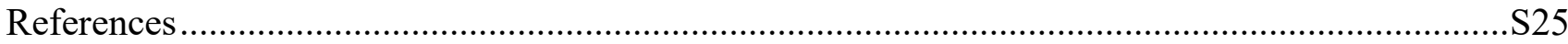




\section{Supplementary Experimental Details}

\section{General experimental details}

Infrared spectra were recorded on a Bruker Tensor 27 ATR-FT-IR. NMR spectra were recorded on either a Bruker AVIII $300 \mathrm{MHz}$, a Bruker DPX $200 \mathrm{MHz}$, or a Bruker DRX $400 \mathrm{MHz}$ as indicated. The spectra were recorded in $\mathrm{CDCl}_{3}$, d6-Acetone, d3-MeCN or d6-DMSO and referenced to the residual proton peak as an internal standard. Electrospray ionisation mass spectra were recorded on a Bruker Esquire 6000 mass spectrometer. Microanalysis was performed by the chair of inorganic chemistry II (ACII) at the Ruhr University Bochum.

\section{$\underline{\text { Single crystal data collection details }}$}

X-ray crystal structure determinations Aligent SuperNova dual S3 wavelength diffractometer employing mirror monochromated $\mathrm{CuK} \alpha$ radiation generated from a SuperNova $(\mathrm{Cu}) \mathrm{X}$-ray Source with an Atlas detector was used for the data collection. Cell constants were obtained from a least squares refinement. Data were collected at $100(2) \mathrm{K}$. The data integration, reduction and absorbtion corrections were undertaken with CrysAlisPro. ${ }^{1}$ The structures were solved using SHELXS ${ }^{2}$ and refined using SHELXL ${ }^{3}$ within the Olex- $2^{4}$ graphical user interface.

\section{Determination of Minimum Inhibitory Concentration (MIC)}

Compounds were tested against Escherichia coli DSM 30083, Acinetobacter baumannii DSM 30007, Pseudomonas aeruginosa DSM 50071, Bacillus subtilis DSM 402, Staphylococcus aureus DSM 20231, and Staphylococcus aureus ATCC 43300 (MRSA) in a microtiter plate assay according to CLSI guidelines, as described by Albada et al. ${ }^{5}$

E. coli, A. baumannii, S. aureus, and B. subtilis were grown in Mueller Hinton broth, P. aeruginosa in cationadjusted Mueller Hinton II. Compounds were dissolved in DMSO 1.25, 2.5, 5 or $10 \mathrm{mg} / \mathrm{mL}$ stock solution. Serial dilution in culture media were prepared with the Tecan Freedom Evo 75 liquid handling workstation (Tecan, Männedorf, Switzerland).

Dilutions, starting from a $10 \mathrm{mg} / \mathrm{mL}$ stock solution, typically covered a range from 512 to $0.5 \mu \mathrm{g} / \mathrm{mL}$. Compound dilutions were inoculated with $5 \times 10^{5}$ bacteria/mL from late exponential cultures grown in the same media. Assay volumes were $200 \mu \mathrm{L}$ per well. Cells were incubated for $16-18$ hours at $37{ }^{\circ} \mathrm{C}$. The lowest compound concentration inhibiting visible bacterial growth was recorded as MIC.

\section{NMR Numbering Scheme and Spectra}
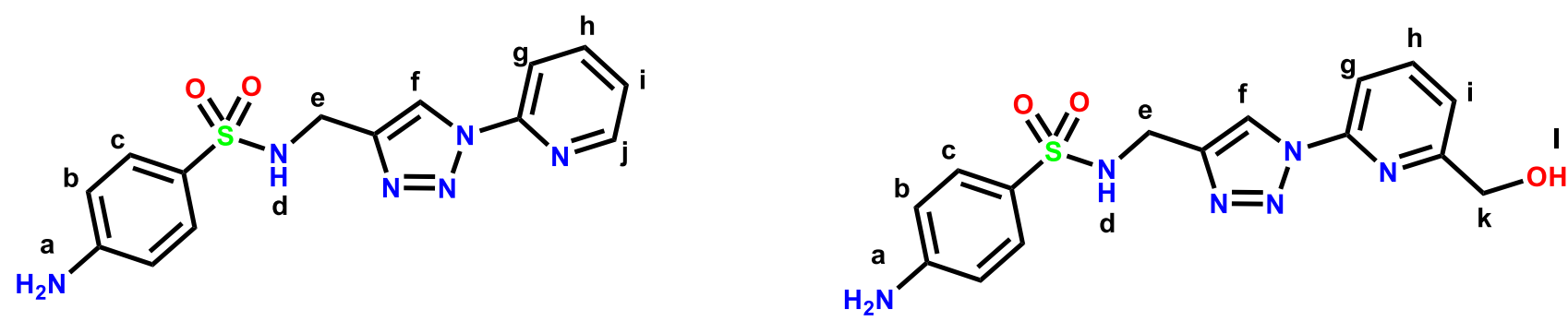

Figure S1. NMR labelling scheme used for the ligands $\mathbf{L}^{\text {tri }}$ (left) and $\mathbf{L}^{\text {tri }} \mathrm{OH}$ (right) and the corresponding rhenium(I) and ruthenium(II) complexes of them. 


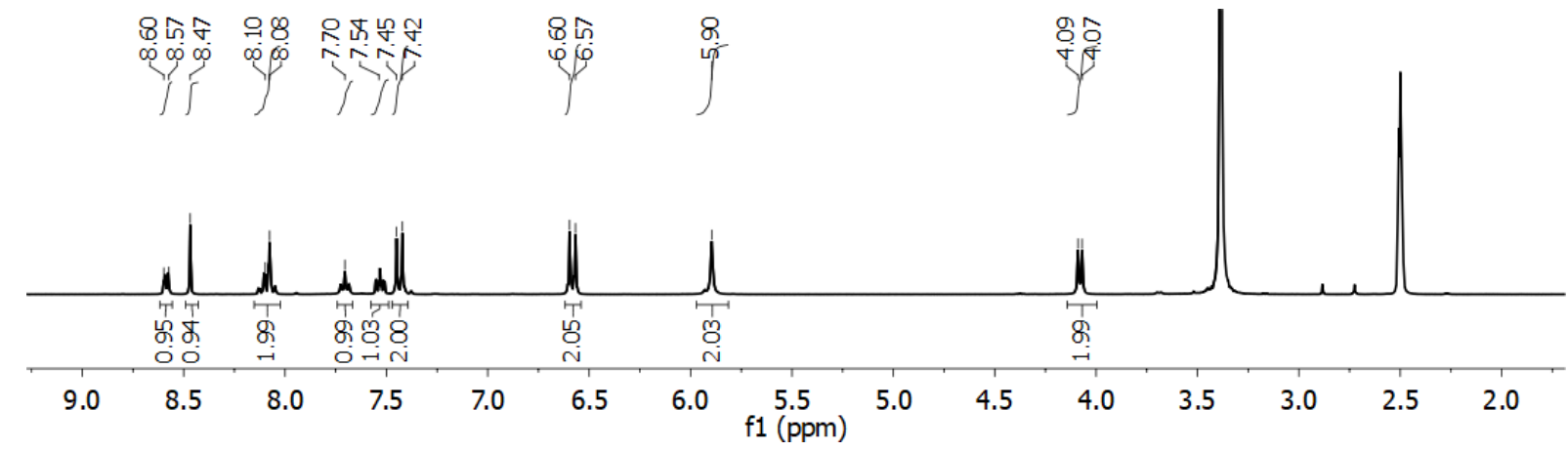

Figure S2. ${ }^{1} \mathrm{H}$ NMR spectrum of $L^{\text {tri }}$ recorded at $300 \mathrm{MHz}$ in d6-DMSO

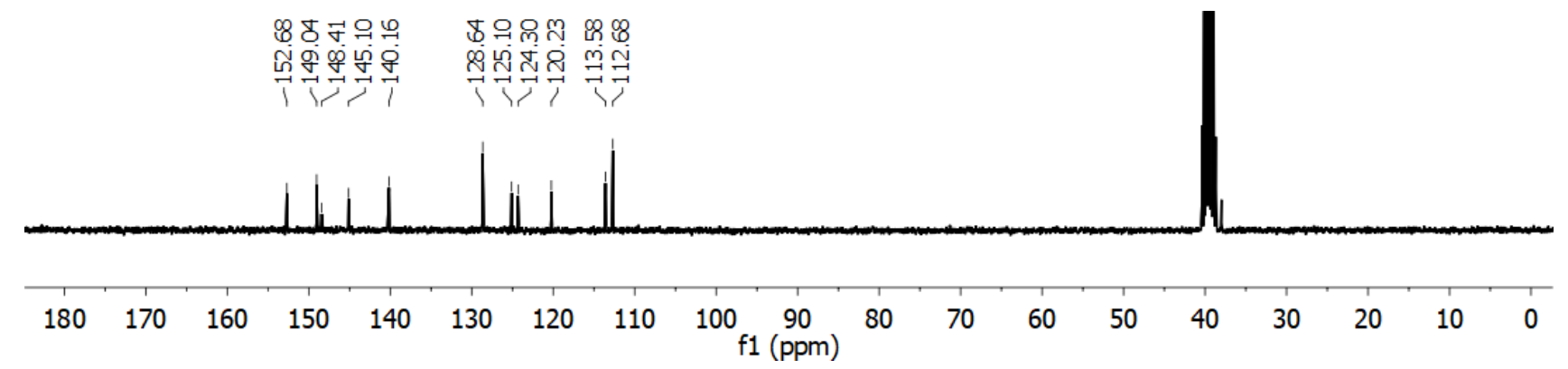

Figure S3. ${ }^{13} \mathrm{C}$ NMR spectrum of $\mathbf{L}^{\text {tri }}$ recorded at $75 \mathrm{MHz}$ in d6-DMSO

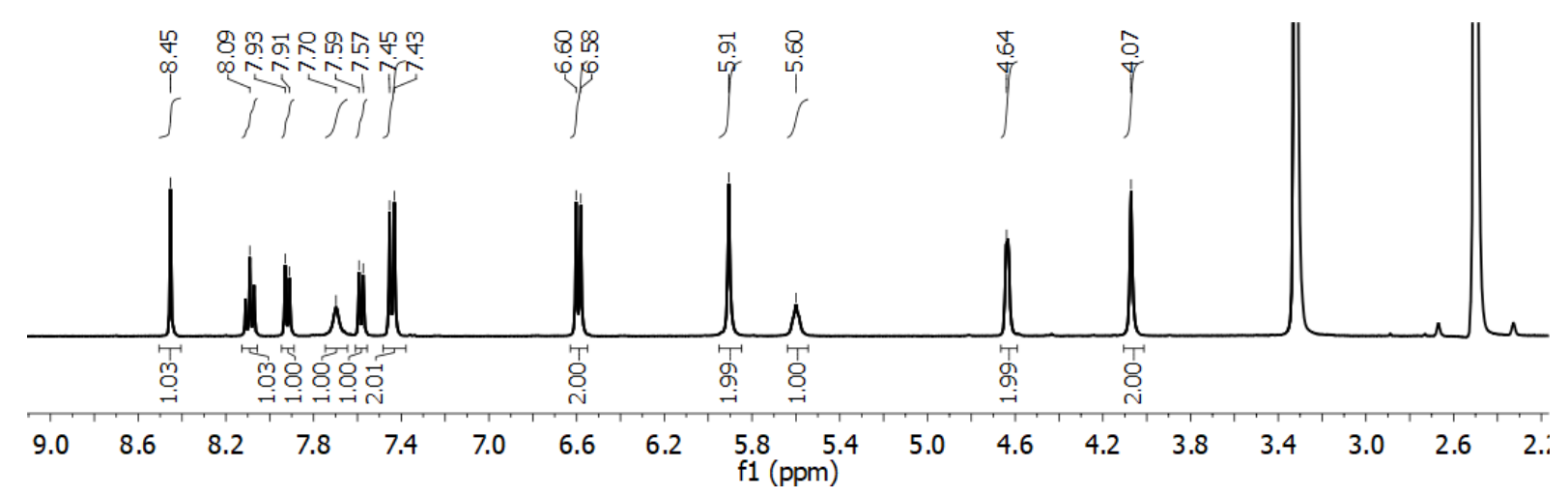

Figure S4. ${ }^{1} \mathrm{H}$ NMR spectrum of $\mathrm{L}^{\text {tri }} \mathrm{OH}$ recorded at $400 \mathrm{MHz}$ in d6-DMSO
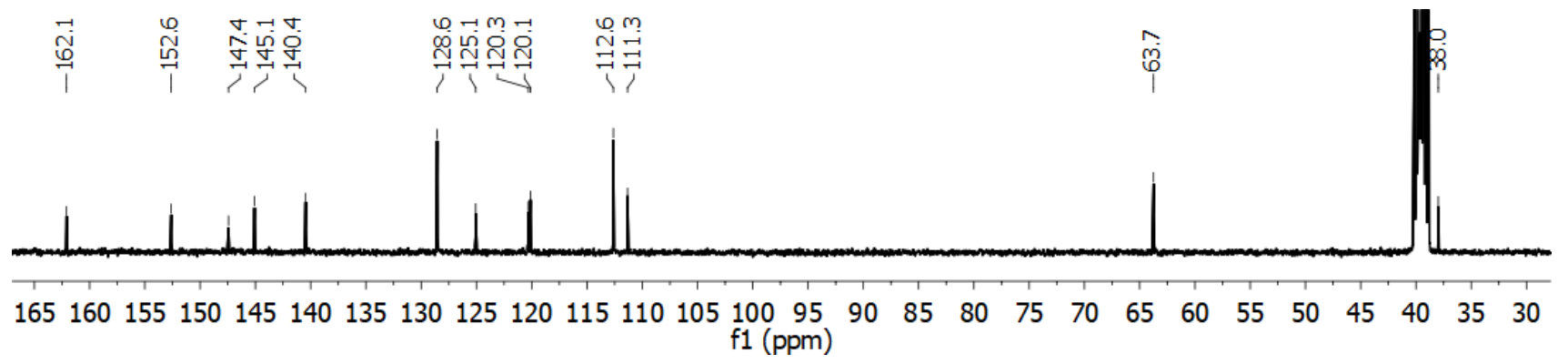

Figure S5. ${ }^{13} \mathrm{C}$ NMR spectrum of $\mathrm{L}^{\text {tri }} \mathrm{OH}$ recorded at $100 \mathrm{MHz}$ in d6-DMSO 


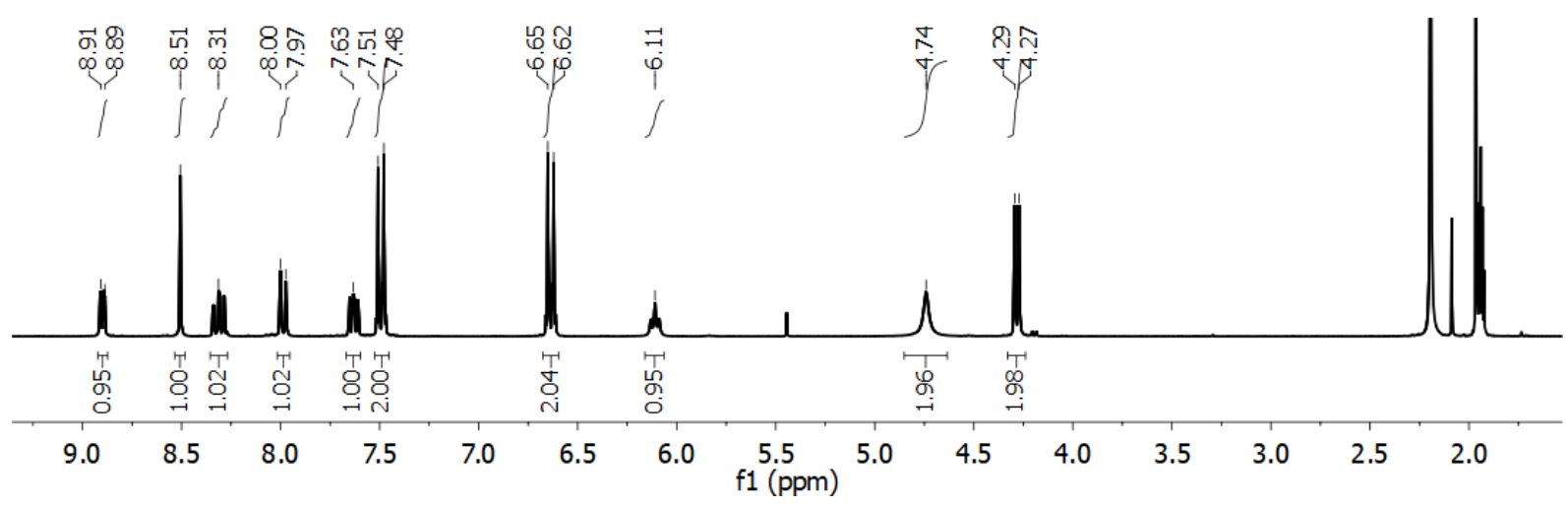

Figure S6. ${ }^{1} \mathrm{H} N \mathrm{NR}$ spectrum of $\left[\operatorname{Re}^{\prime}\left(\mathrm{L}^{\text {tri }}\right)(\mathrm{CO})_{3} \mathrm{Cl}\right]$ recorded at $300 \mathrm{MHz}$ in d3-MeCN

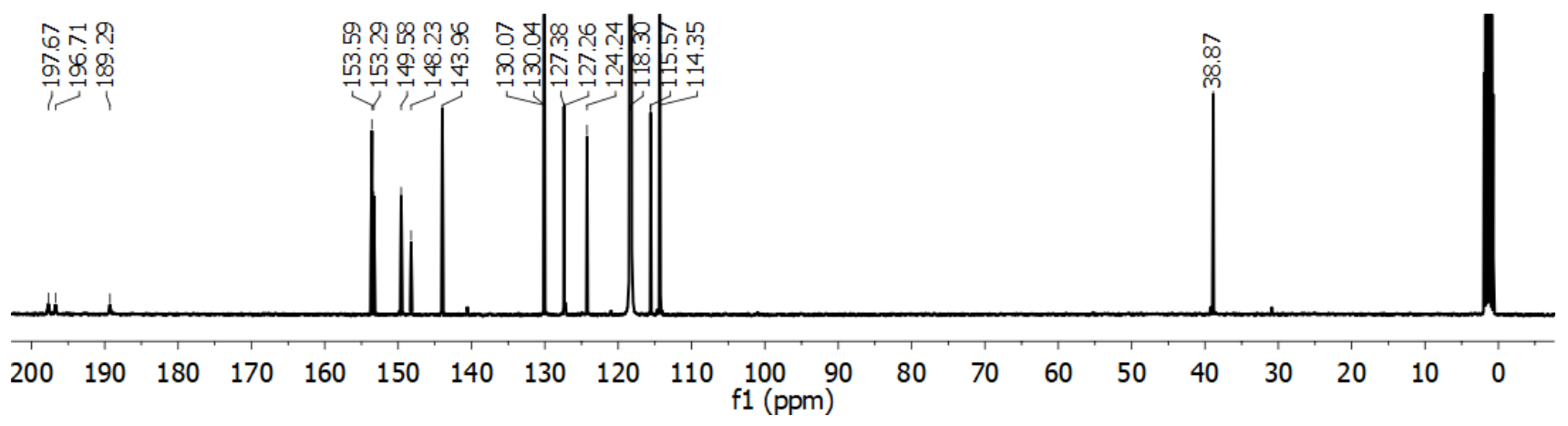

Figure S7. ${ }^{13} \mathrm{C} N M R$ spectrum of $\left[\operatorname{Re}^{\prime}\left(\mathrm{L}^{\text {tri }}\right)(\mathrm{CO})_{3} \mathrm{Cl}\right]$ recorded at $100 \mathrm{MHz}$ in d3-MeCN
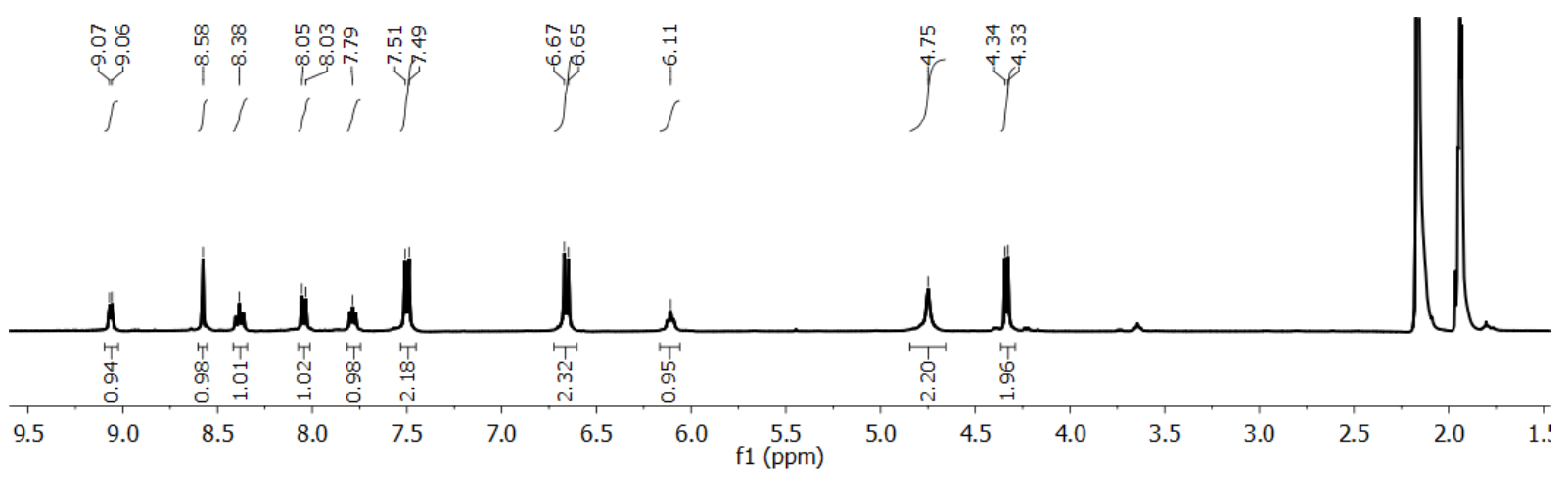

Figure S8. ${ }^{1} \mathrm{H}$ NMR spectrum of $\left[\mathrm{Ru}^{\prime \prime}\left(\mathrm{L}^{\text {tri }}\right)(\mathrm{CO})_{2} \mathrm{Cl}_{2}\right]$ recorded at $400 \mathrm{MHz}$ in d3-MeCN

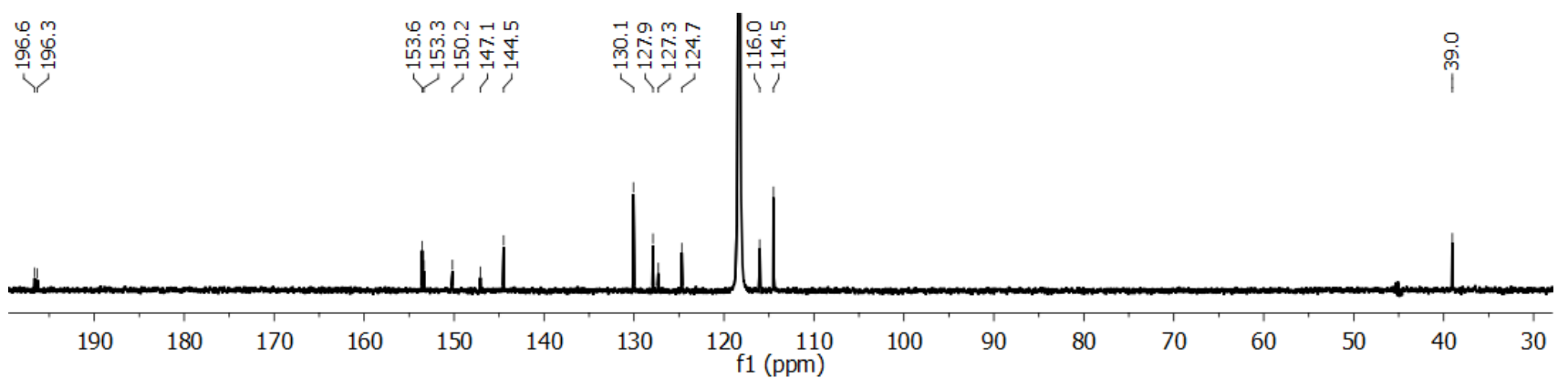

Figure S9. ${ }^{13} \mathrm{C} N \mathrm{MR}$ spectrum of $\left[\mathrm{Ru}^{\prime \prime}\left(\mathrm{L}^{\text {tri }}\right)(\mathrm{CO})_{2} \mathrm{Cl}_{2}\right]$ recorded at $100 \mathrm{MHz}$ in d3-MeCN 


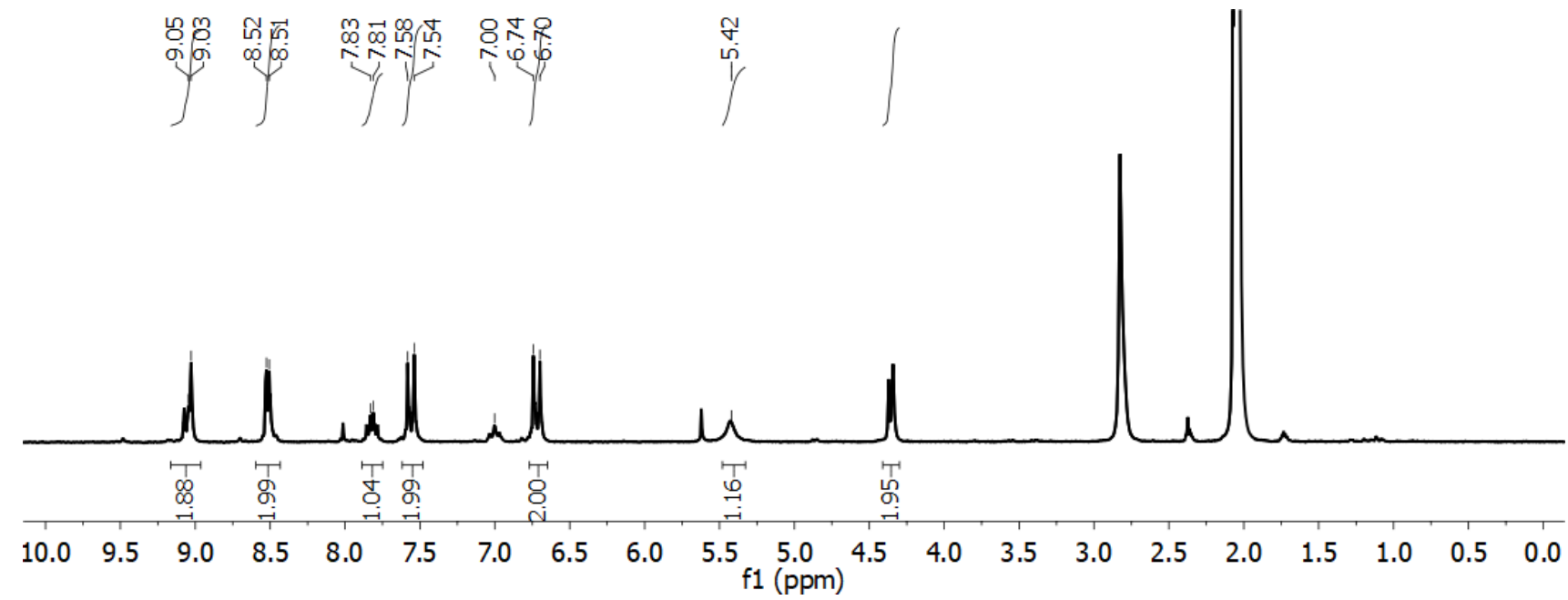

Figure S10. ${ }^{1} \mathrm{H} N \mathrm{NR}$ spectrum of $\left[\mathrm{Re}^{\prime}\left(\mathrm{L}^{\text {tri }}\right)(\mathrm{CO})_{3} \mathrm{Br}\right]$ recorded at $300 \mathrm{MHz}$ in d6-acetone

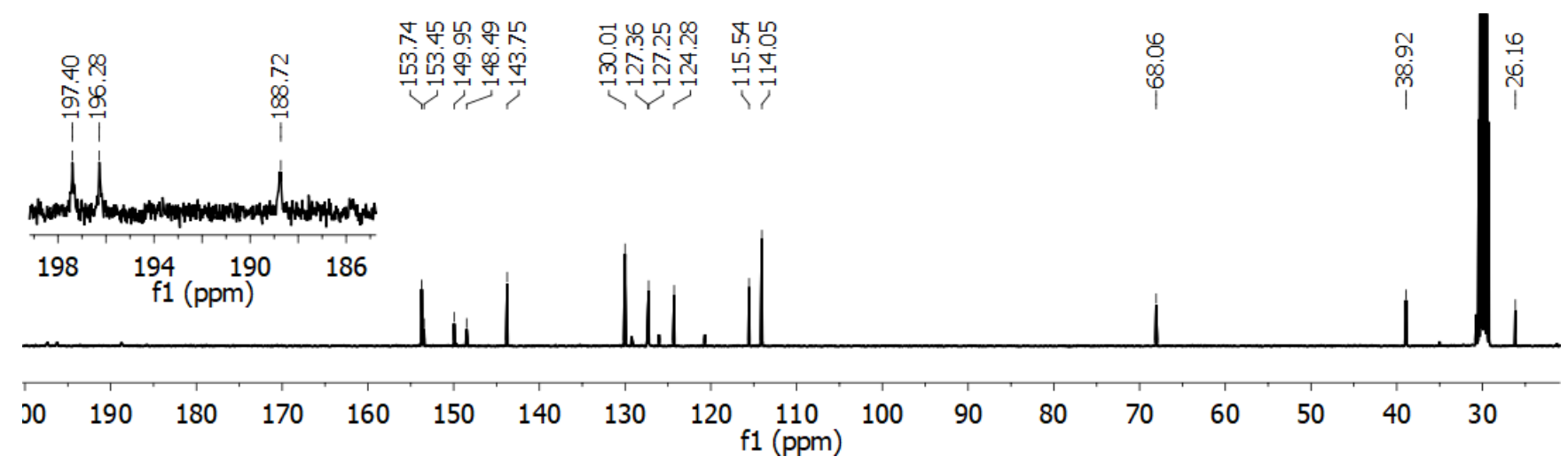

Figure $\mathrm{S} 11 .{ }^{13} \mathrm{C} N \mathrm{NMR}$ spectrum of $\left[\mathrm{Re}^{\prime}\left(\mathrm{L}^{\text {tri }}\right)(\mathrm{CO})_{3} \mathrm{Br}\right]$ recorded at $100 \mathrm{MHz}$ in d6-acetone

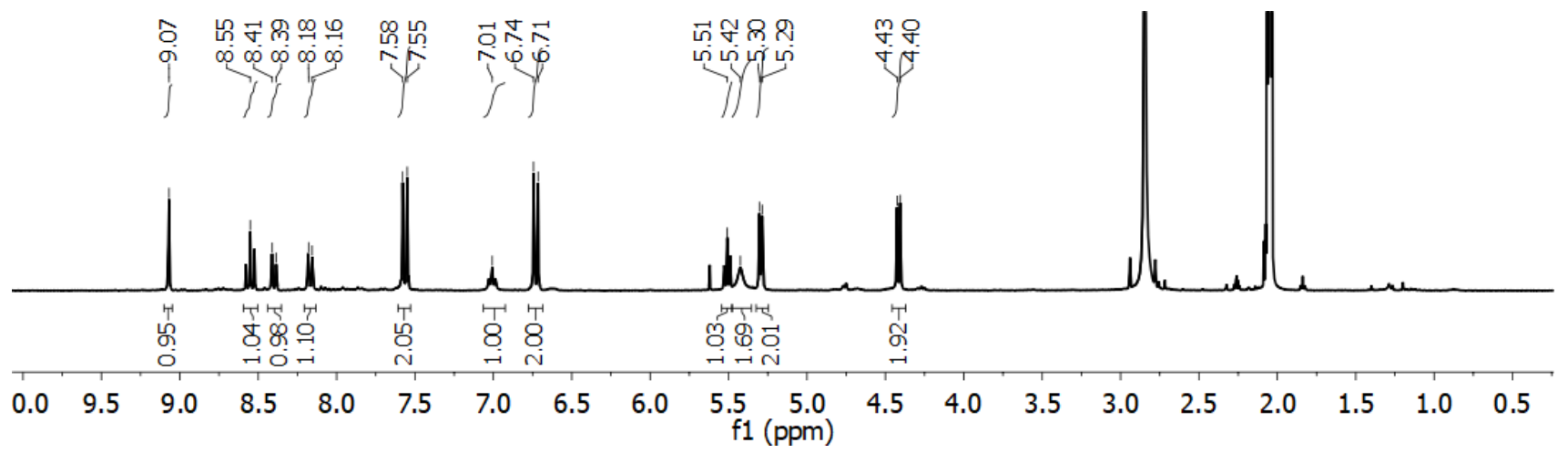

Figure S12. ${ }^{1} \mathrm{H} N \mathrm{NR}$ spectrum of $\left[\mathrm{Ru}^{\prime \prime}\left(\mathrm{L}^{\text {tri }} \mathrm{OH}\right)(\mathrm{CO})_{2} \mathrm{Cl}_{2}\right]$ recorded at $300 \mathrm{MHz}$ in d6-acetone. 


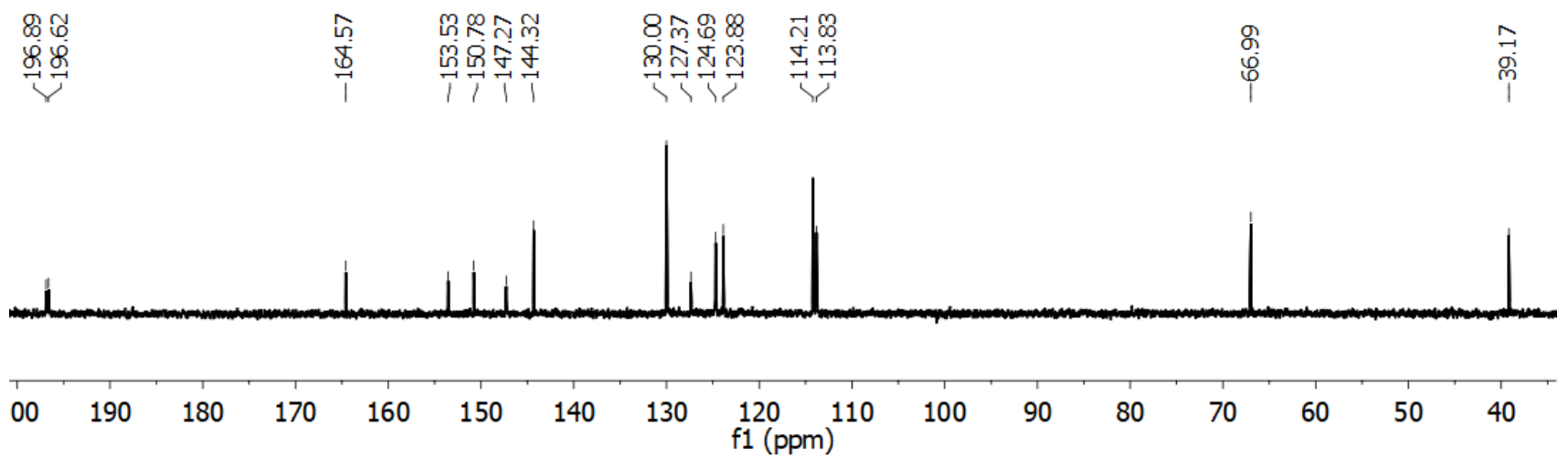

Figure S13. ${ }^{13} \mathrm{C} \mathrm{NMR}$ spectrum of $\left[\mathrm{Ru}^{\prime \prime}\left(\mathrm{L}^{\text {tri }} \mathrm{OH}\right)(\mathrm{CO})_{2} \mathrm{Cl}_{2}\right]$ recorded at $100 \mathrm{MHz}$ in d6-acetone.

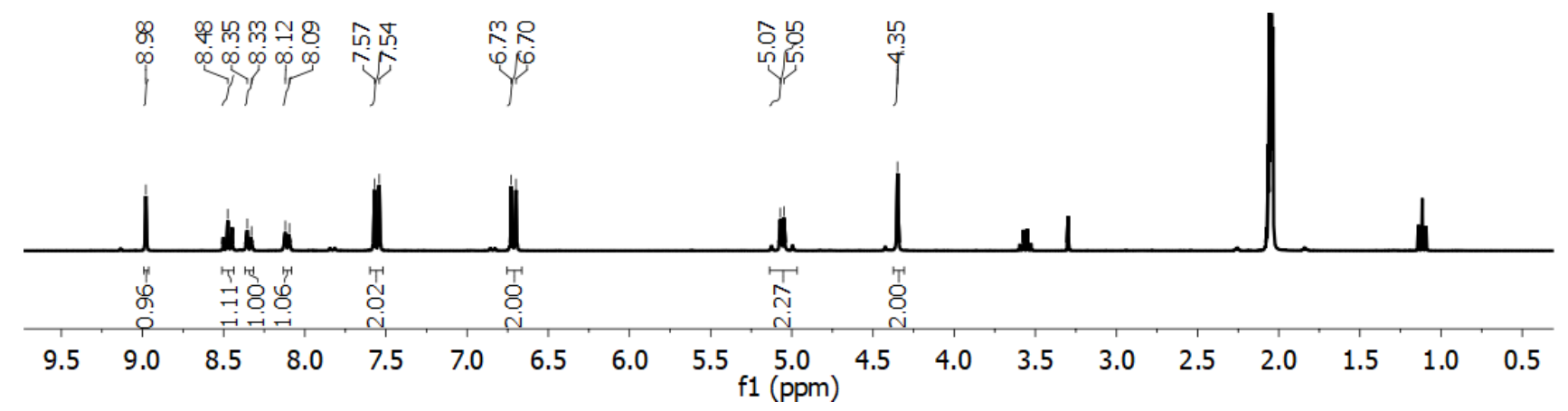

Figure S14. ${ }^{1} \mathrm{H} N \mathrm{NMR}$ spectrum of $\left[\mathrm{Re}^{\prime}\left(\mathrm{L}^{\text {tri } \mathrm{OH}}\right)(\mathrm{CO})_{3} \mathrm{Cl}\right]$ recorded at $300 \mathrm{MHz}$ in d6-acetone. Peaks at $1.12 \mathrm{ppm}$ and $3.57 \mathrm{ppm}$ are due to residual ethanol.

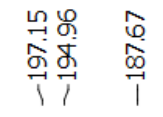

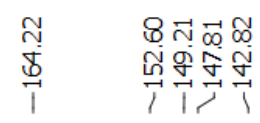

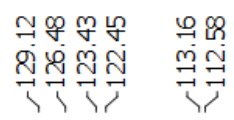
$\stackrel{\substack{\infty \\ \varphi}}{\varphi}$

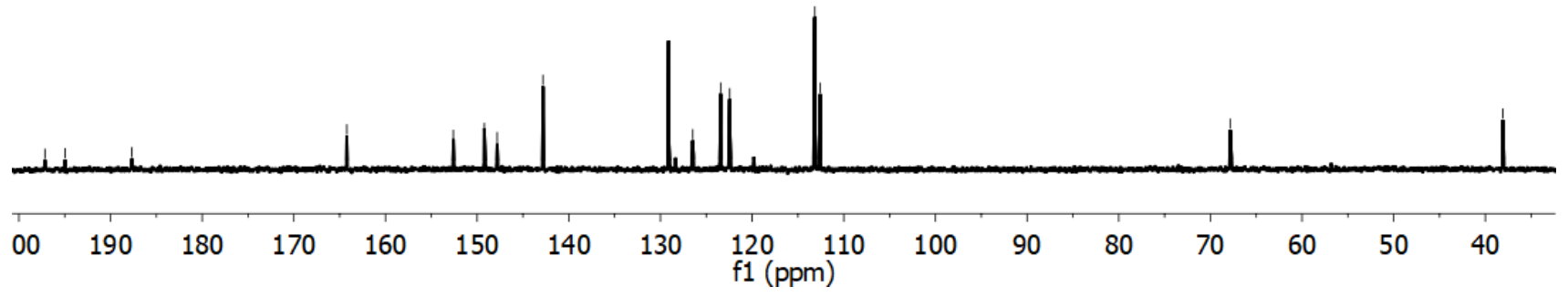

Figure S15. ${ }^{13} \mathrm{C} \mathrm{NMR}$ spectrum of $\left[\operatorname{Re}^{l}\left(\mathrm{~L}^{\text {tri }} \mathrm{OH}\right)(\mathrm{CO}){ }_{3} \mathrm{Cl}\right]$ recorded at $100 \mathrm{MHz}$ in d6-acetone. 


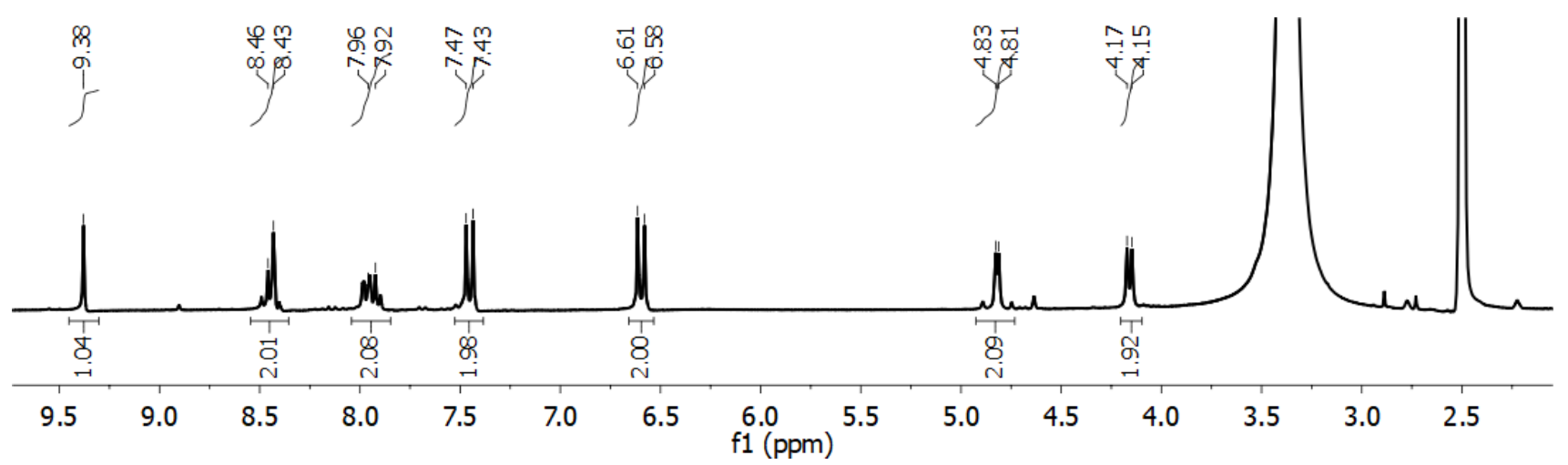

Figure S16. ${ }^{1} \mathrm{H} N M R$ spectrum of $\left[\operatorname{Re}^{\prime}\left(\mathrm{L}^{\text {tri } \mathrm{OH}}\right)(\mathrm{CO})_{3} \mathrm{Cl}\right]$ recorded at $300 \mathrm{MHz}$ in d6-DMSO.
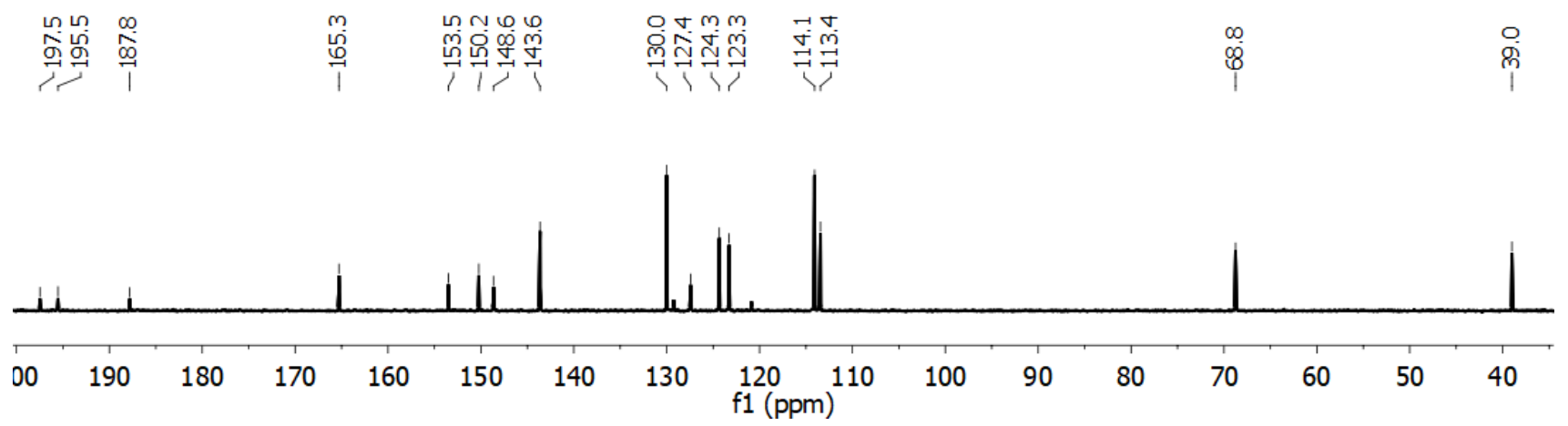

Figure S17. ${ }^{13} \mathrm{C} N M R$ spectrum of $\left[\operatorname{Re}^{\prime}\left(\mathrm{L}^{\text {tri }} \mathrm{OH}\right)(\mathrm{CO}){ }_{3} \mathrm{Cl}\right]$ recorded at $100 \mathrm{MHz}$ in d6-acetone. 


\section{Mass Spectra}

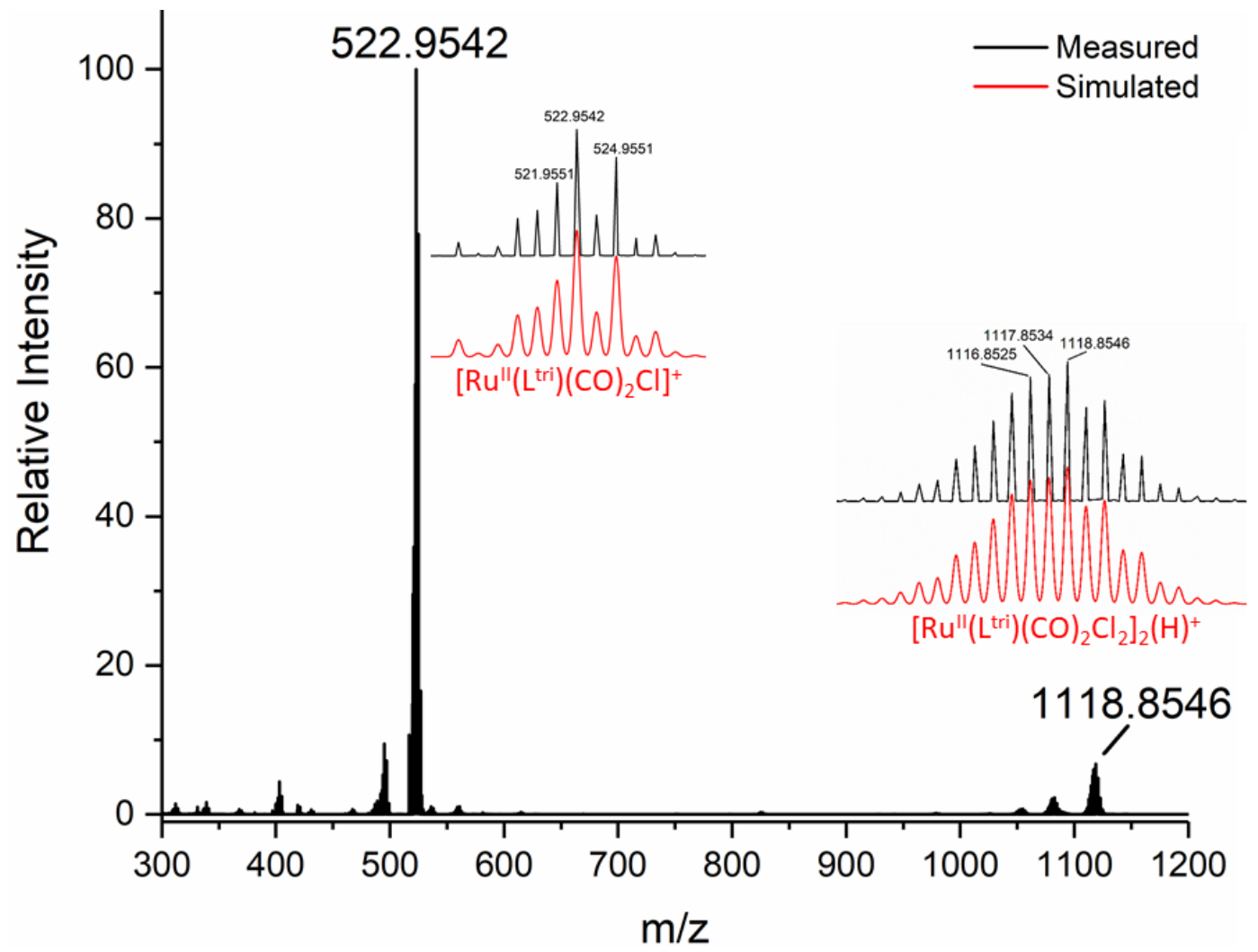

Figure S18. HR-ESI-MS spectrum of [Ru'l(Ltri) $\left.(\mathrm{CO})_{2} \mathrm{Cl}_{2}\right]$.

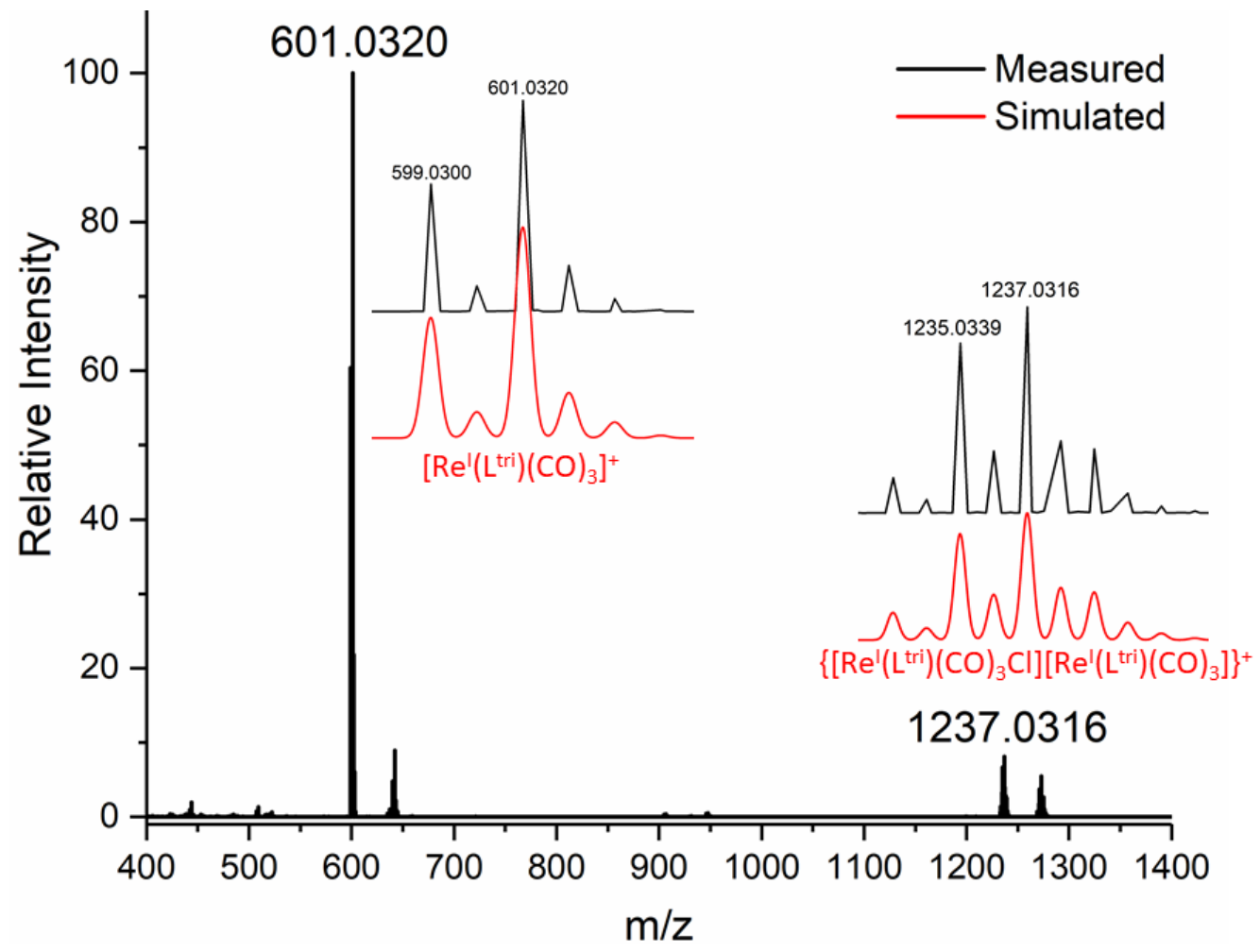

Figure S19. HR-ESI-MS spectrum of $\left[\operatorname{Re}^{\prime}\left(\mathrm{L}^{\text {tri }}\right)(\mathrm{CO})_{3} \mathrm{Cl}\right]$. 


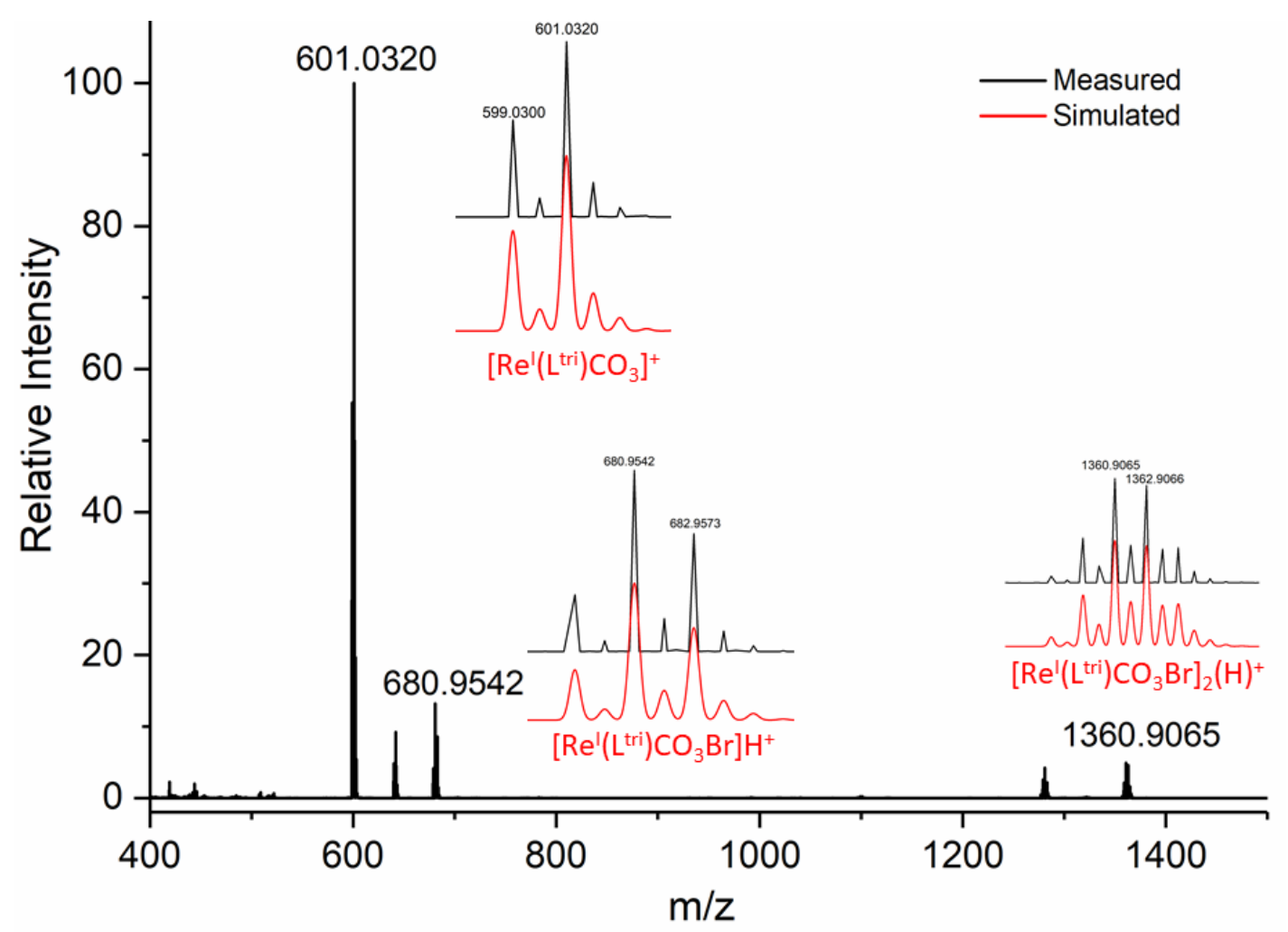

Figure S2O. HR-ESI-MS spectrum of $\left[\operatorname{Re}^{\prime}\left(\mathrm{L}^{\text {tri }}\right)(\mathrm{CO})_{3} \mathrm{Br}\right]$

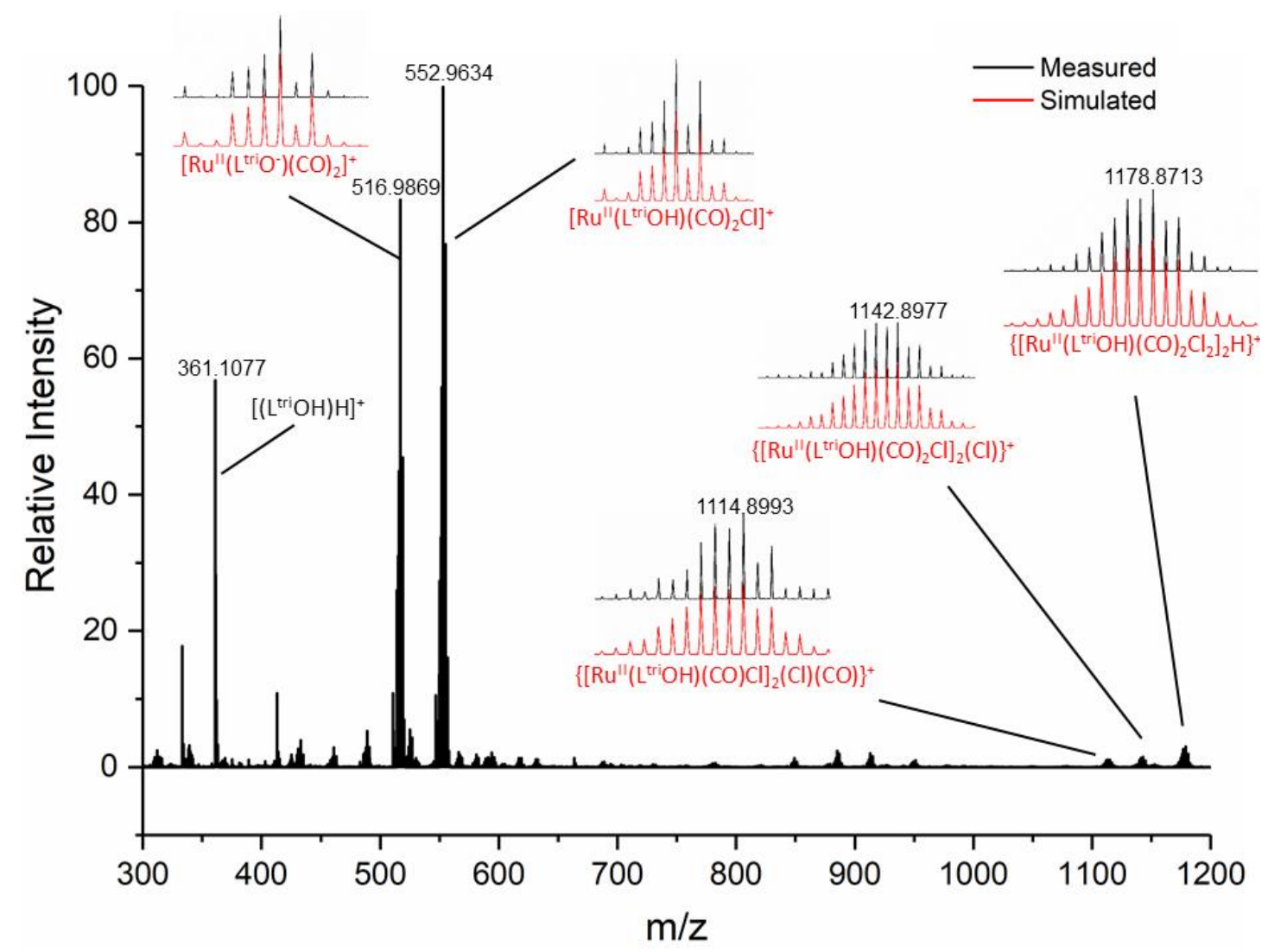

Figure S21. HR-ESI-MS spectrum of $\left[\mathrm{Ru}^{\prime \prime}\left(\mathrm{L}^{\text {triOH}} \mathrm{OH}(\mathrm{CO})_{2} \mathrm{Cl}_{2}\right]\right.$. 


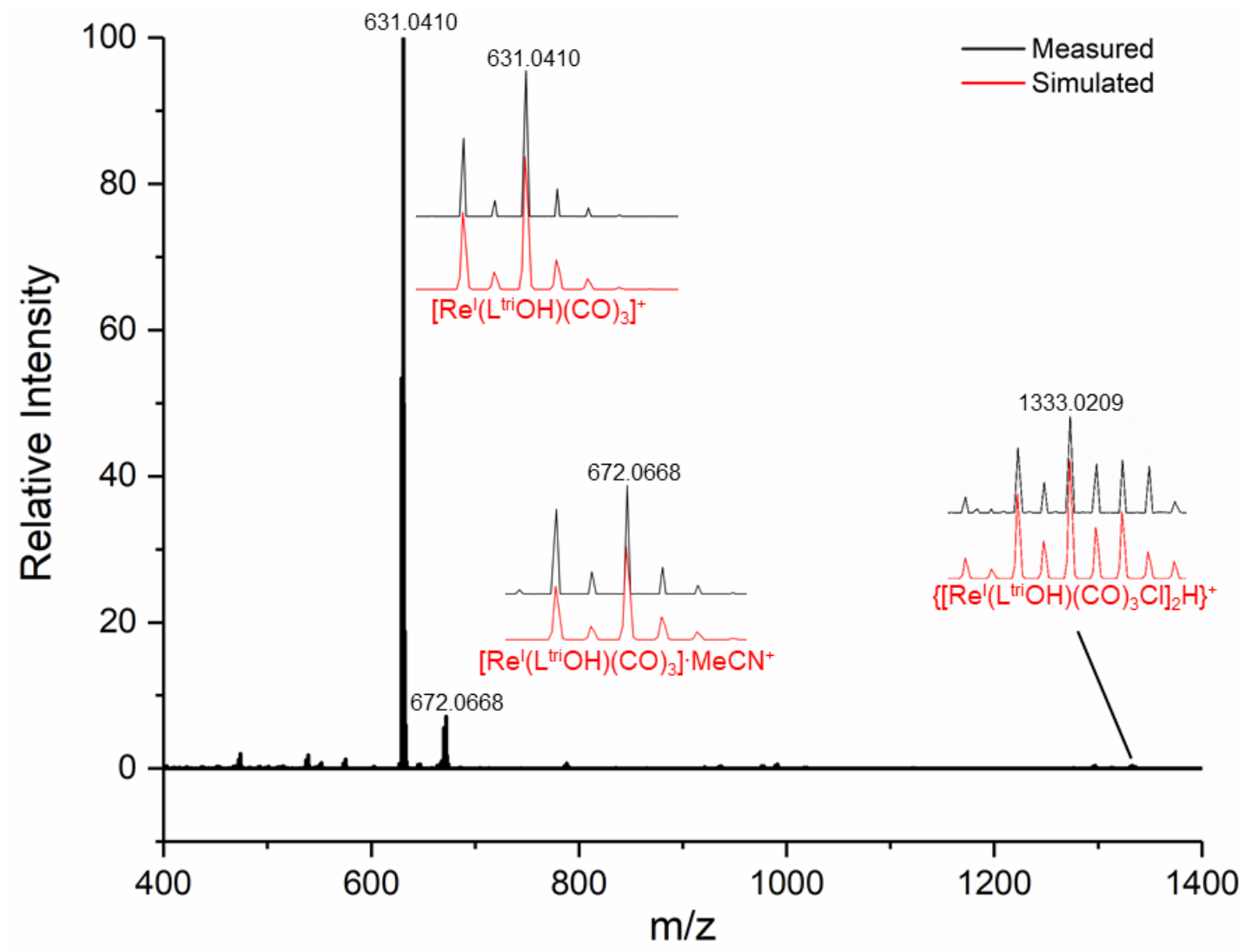

Figure S22. HR-ESI-MS spectrum of $\left[\operatorname{Re}^{\prime}\left(\mathrm{L}^{\text {triOH}} \mathrm{OH}(\mathrm{CO})_{3} \mathrm{Cl}\right]\right.$

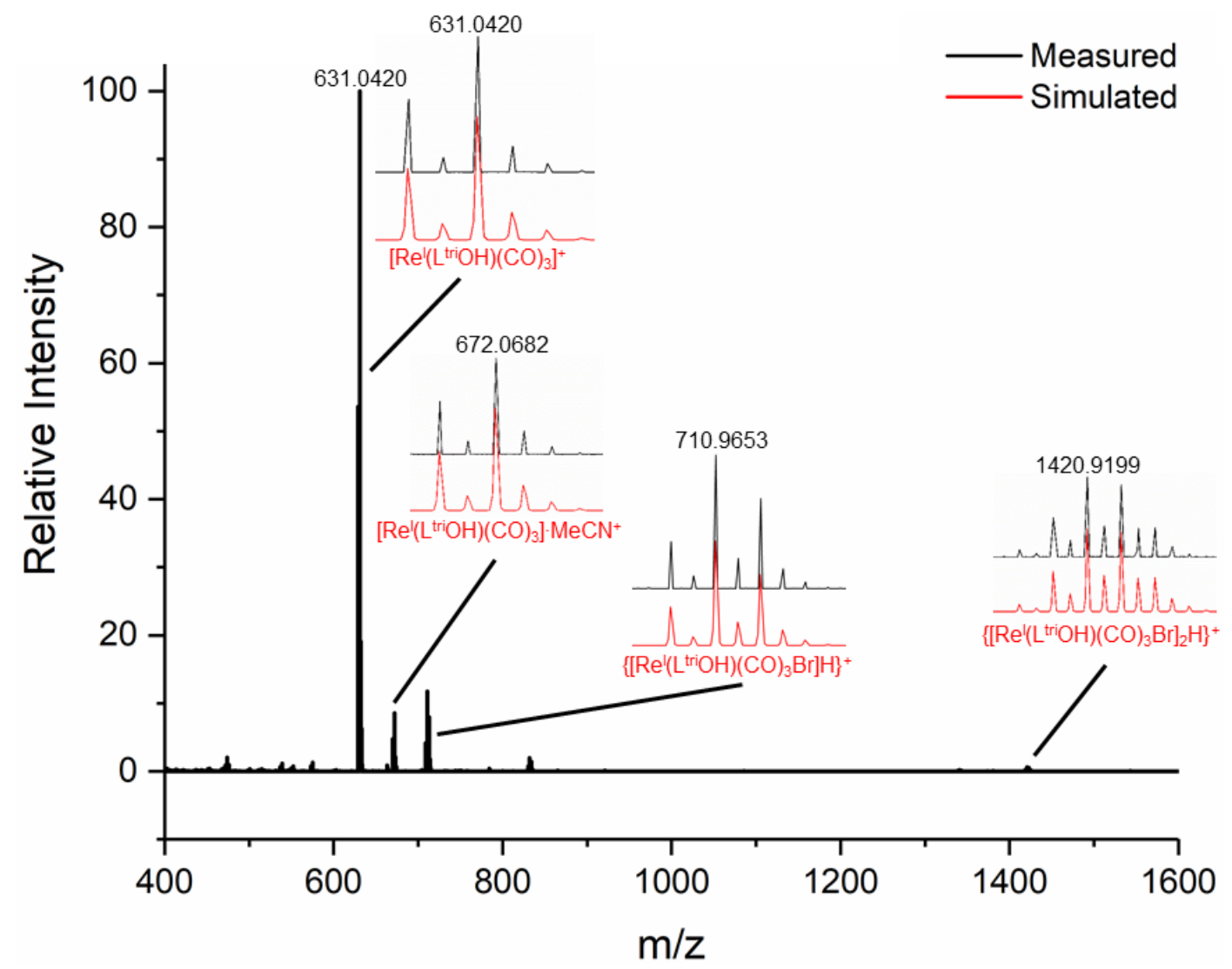

Figure S23. HR-ESI-MS spectrum of $\left[\operatorname{Re}^{\prime}\left(\mathrm{L}^{\text {tri }} \mathrm{OH}\right)(\mathrm{CO})_{3} \mathrm{Br}\right]$ 


\section{Crystallographic Data Tables}

Table S1. Full crystal structure determination details for $\left[\operatorname{Re}^{\prime}\left(\mathrm{L}^{\text {tri }}\right)(\mathrm{CO})_{3} \mathrm{Cl}\right]$ Polymorph $A$ and $B,\left[\operatorname{Re}^{\prime}\left(\mathrm{L}^{\text {tri }} \mathrm{OH}\right)(\mathrm{CO})_{3} B r\right]$ and $\left[\operatorname{Re}^{\prime}\left(\mathrm{L}^{\text {tri }}\right)(\mathrm{CO})_{3} B r\right]$.

\begin{tabular}{|c|c|c|c|c|}
\hline & $\begin{array}{l}{\left[\operatorname{Re}^{I}\left(\boldsymbol{L}^{\text {tri }}\right)(\mathrm{CO})_{3} \mathrm{Cl}\right]} \\
\text { Polymorph A }\end{array}$ & $\begin{array}{l}{\left[\operatorname{Re}^{I}\left(\boldsymbol{L}^{\text {tri }}\right)(\mathrm{CO})_{3} \mathrm{Cl}\right]} \\
\text { Polymorph B }\end{array}$ & {$\left[\operatorname{Re}^{I}\left(\boldsymbol{L}^{\text {tri }} \boldsymbol{O H}\right)(\mathrm{CO})_{3} B r\right]$} & {$\left[\operatorname{Re}^{I}\left(\boldsymbol{L}^{\operatorname{tri}}\right)(\mathrm{CO})_{3} \mathrm{Br}\right]$} \\
\hline CCDC number & 1909704 & 1909705 & 1909708 & 1909707 \\
\hline Empirical formula & $\mathrm{C}_{20} \mathrm{H}_{20} \mathrm{ClN}_{6} \mathrm{O}_{6} \mathrm{ReS}$ & $\mathrm{C}_{17} \mathrm{H}_{14} \mathrm{ClN}_{6} \mathrm{O}_{5} \mathrm{ReS}$ & $\mathrm{C}_{19} \mathrm{H}_{18} \mathrm{BrN}_{4} \mathrm{O}_{6} \mathrm{ReS}$ & $\mathrm{C}_{18} \mathrm{H}_{18} \mathrm{BrN}_{6} \mathrm{O}_{6} \mathrm{ReS}$ \\
\hline$M_{r}$ & 694.14 & 1163.68 & 696.54 & 712.55 \\
\hline Crystal system & Monoclinic & Monoclinic & Tetragonal & Monoclinic \\
\hline Space group & $P 2{ }_{1} / c$ & $P n$ & $I 4_{1} / a$ & $P n$ \\
\hline$a[\AA]$ & $23.6871(10)$ & $7.0610(3)$ & $36.2932(9)$ & $7.1181(3)$ \\
\hline$b[\AA]$ & $10.8058(3)$ & $15.8387(5)$ & $36.2932(9)$ & $15.9522(6)$ \\
\hline$c[\AA]$ & $9.2411(3)$ & $10.9050(6)$ & $6.9795(3)$ & $10.9472(5)$ \\
\hline$\alpha\left[^{\circ}\right]$ & 90 & 90 & 90 & 90 \\
\hline$\beta\left[^{\circ}\right]$ & $95.636(4)$ & $107.415(5)$ & 90 & $108.182(5)$ \\
\hline$\gamma\left[^{\circ}\right]$ & 90 & 90 & 90 & 90 \\
\hline$V\left[\AA^{3}\right]$ & $2353.90(14)$ & $1163.68(9)$ & $9193.4(6)$ & $1180.97(9)$ \\
\hline $\mathrm{Z}$ & 4 & 2 & 16 & 2 \\
\hline $\mathrm{T}[\mathrm{K}]$ & $106(2)$ & $106(2)$ & $104(2)$ & $109(2)$ \\
\hline$\rho_{\text {calcd. }}\left[\mathrm{gcm}^{-3}\right]$ & 1.959 & 1.815 & 2.013 & 2.004 \\
\hline$\mu\left[\mathrm{mm}^{-1}\right]$ & 12.419 & 12.461 & 13.655 & 13.288 \\
\hline $\mathrm{F}(000)$ & 1352 & 612 & 5440 & 684 \\
\hline Crystal size $[\mathrm{mm}]$ & $0.1 \times 0.01 \times 0.01$ & $0.13 \times 0.08 \times 0.04$ & $0.09 \times 0.01 \times 0.01$ & $0.1 \times 0.03 \times 0.01$ \\
\hline$\Theta$ range $\left[{ }^{\circ}\right]$ & 3.75 to 74.50 & 5.09 to 74.70 & 6.89 to 125.02 & 5.08 to 74.36 \\
\hline Reflections collected & 23133 & 11125 & 23652 & 8787 \\
\hline$R$ (int) & 0.0540 & 0.0344 & 0.0979 & 0.0386 \\
\hline Max. and min. transmission & 0.305 and 1.000 & 0.307 and 1.00 & 0.23221 and 1.000 & 0.4864 and 1.00 \\
\hline Data/restraints/parameters & $4740 / 36 / 346$ & $4257 / 8 / 281$ & $3633 / 9 / 303$ & $4334 / 14 / 300$ \\
\hline Goof $\left(\mathrm{F}^{2}\right)$ & 1.141 & 1.109 & 1.025 & 1.105 \\
\hline $\mathrm{R}_{1}[\mathrm{I}>2 \sigma(\mathrm{I})]$ & 0.0501 & 0.0340 & 0.0453 & 0.0388 \\
\hline $\mathrm{wR}_{2}[\mathrm{I}>2 \sigma(\mathrm{I})]$ & 0.1075 & 0.0865 & 0.0846 & 0.1099 \\
\hline $\mathrm{R}_{1}$ [all data] & 0.0562 & 0.0351 & 0.0686 & 0.0398 \\
\hline$w \mathrm{R}_{2}$ [all data] & 0.1048 & 0.0871 & 0.0928 & 0.1110 \\
\hline Largest diff. peak and hole $\left[\mathrm{e}^{-3}\right]$ & 2.196 and -3.050 & 1.292 and -1.541 & 1.82 and -1.00 & 0.999 and -1.265 \\
\hline
\end{tabular}


Table S2. Full crystal structure determination details for $\mathbf{L}^{\text {tri }} \mathrm{OH}$ and $\left[\mathrm{Ru}^{\prime \prime}\left(\mathrm{L}^{\text {tri }}\right)(\mathrm{CO})_{2} \mathrm{Cl}_{2}\right]$.

\begin{tabular}{|c|c|c|c|}
\hline & $L^{\text {tri }} \mathrm{OH}$ & {$\left[\mathrm{Ru} u^{I I}\left(\mathrm{~L}^{t r i}\right)(\mathrm{CO})_{2} \mathrm{Cl}_{2}\right]$} & \\
\hline CCDC number & 1909706 & 1909703 & \\
\hline Empirical formula & $\mathrm{C}_{15} \mathrm{H}_{16} \mathrm{~N}_{6} \mathrm{O}_{3} \mathrm{~S}$ & $\mathrm{C}_{19} \mathrm{H}_{20} \mathrm{Cl}_{2} \mathrm{~N}_{6} \mathrm{O}_{5} \mathrm{RuS}$ & \\
\hline$M_{r}$ & 360.40 & 616.44 & \\
\hline Crystal system & Monoclinic & Monoclinic & \\
\hline Space group & $P 2{ }_{1} / n$ & $P 2{ }_{1} / c$ & \\
\hline$a[\AA]$ & $7.9529(6)$ & $23.4359(6)$ & \\
\hline$b[\AA]$ & $19.4477(12)$ & $10.8409(4)$ & \\
\hline$c[\AA]$ & $10.5621(7)$ & $9.2297(3)$ & \\
\hline$\alpha\left[^{\circ}\right]$ & 90 & 90 & \\
\hline$\beta\left[^{\circ}\right]$ & $102.370(7)$ & 94.852 & \\
\hline$\gamma\left[{ }^{\circ}\right]$ & 90 & 90 & \\
\hline$V\left[\AA^{3}\right]$ & $1595.67(19)$ & $2336.55(13)$ & \\
\hline $\mathrm{Z}$ & 4 & 4 & \\
\hline $\mathrm{T}[\mathrm{K}]$ & $104(2)$ & $104(2)$ & \\
\hline$\rho_{\text {calcd. }}\left[\mathrm{gcm}^{-3}\right]$ & 1.500 & 1.752 & \\
\hline$\mu\left[\mathrm{mm}^{-1}\right]$ & 2.075 & 8.770 & \\
\hline $\mathrm{F}(000)$ & 752 & 1240 & \\
\hline Crystal size $[\mathrm{mm}]$ & $0.1 \times 0.01 \times 0.01$ & $0.27 \times 0.14 \times 0.09$ & \\
\hline$\Theta$ range $\left[{ }^{\circ}\right]$ & 4.547 to 73.571 & 3.73 to 74.240 & \\
\hline Reflections collected & 9028 & 17078 & \\
\hline$R$ (int) & 0.0369 & 0.0362 & \\
\hline Max. and min. transmission & 0.486 and 1.000 & 0.868 and 0.868 & \\
\hline Data/restraints/parameters & $3151 / 0 / 228$ & $4676 / 0 / 310$ & \\
\hline Goof $\left(\mathrm{F}^{2}\right)$ & 1.030 & 1.051 & \\
\hline $\mathrm{R}_{1}[\mathrm{I}>2 \sigma(\mathrm{I})]$ & 0.0368 & 0.0394 & \\
\hline $\mathrm{wR}_{2}[\mathrm{I}>2 \sigma(\mathrm{I})]$ & 0.0843 & 0.0966 & \\
\hline $\mathrm{R}_{1}$ [all data] & 0.0511 & 0.0501 & \\
\hline$w \mathrm{R}_{2}$ [all data] & 0.0914 & 0.1042 & \\
\hline Largest diff. peak and hole $\left[\mathrm{e}^{-3}\right]$ & 0.198 and -0.380 & 0.909 and -1.019 & \\
\hline
\end{tabular}




\section{Supplementary Structural Data}

Table S3. Intermolecular interactions of the 'extended' complexes

\begin{tabular}{|c|c|c|}
\hline & $\begin{array}{l}{\left[\operatorname{Re}^{I}\left(\boldsymbol{L}^{\text {tri }}\right)(\mathrm{CO})_{3} \mathrm{Cl}\right]} \\
\text { Polymorph A }\end{array}$ & {$\left[\mathrm{Ru}^{I I}\left(\boldsymbol{L}^{\text {tri }}\right)(\mathrm{CO})_{2} \mathrm{Cl}_{2}\right]$} \\
\hline \multicolumn{3}{|c|}{ Intermolecular Pi-Pi interactions } \\
\hline $\operatorname{Tri}_{\text {centroid }} \cdots \mathrm{Py}_{\text {centroid }}(\AA)$ & 3.668 & 3.709 \\
\hline $\mathrm{C}(9)_{\text {tri }} \cdots$ Pycentroid $(\AA)$ & 3.398 & 3.373 \\
\hline $\mathrm{C}(9)_{\mathrm{tri}} \cdots \mathrm{C}(11 \mathrm{~B})_{\mathrm{py}}(\AA)^{a}$ & $3.47(1)$ & $3.441(5)$ \\
\hline \multicolumn{3}{|c|}{ Intermolecular $\mathrm{NH}-\mathrm{Pi}$ interactions } \\
\hline $\mathrm{NH}_{2}(1) \cdots \mathrm{Ph}_{\text {centroid }}(\AA)$ & 3.372 & 3.345 \\
\hline \multicolumn{3}{|c|}{ Intermolecular H-bonding } \\
\hline $\mathrm{N}(1)-\mathrm{H} \cdots \mathrm{O}(2 \mathrm{~A})(\AA)$ & $3.031(9)$ & 3.070 \\
\hline$>\mathrm{N}(1)-\mathrm{H} \cdots \mathrm{O}(2 \mathrm{~A})\left(^{\circ}\right)$ & 113.6 & 151.0 \\
\hline $\mathrm{N}(2)-\mathrm{H} \cdots \mathrm{O}(1 \mathrm{~B})(\AA)$ & $2.936(8)$ & $2.940(5)$ \\
\hline$>\mathrm{N}(2)-\mathrm{H} \cdots \mathrm{O}(1 \mathrm{~B})\left(^{\circ}\right)$ & 113.63 & 114.0 \\
\hline
\end{tabular}

${ }^{a}$ Closest contacts

Table S4. Intra-/Intermolecular Interactions of the 'folded' complexes

\begin{tabular}{|c|c|c|c|}
\hline & $\begin{array}{l}{\left[\operatorname{Re}^{I}\left(\boldsymbol{L}^{\text {tri }}\right)(\mathrm{CO})_{3} \mathrm{Cl}\right]} \\
\text { Polymorph B }\end{array}$ & {$\left[\operatorname{Re}^{I}\left(\boldsymbol{L}^{\text {tri }} \boldsymbol{O H}\right)(C O)_{3} \mathrm{Br}\right]$} & {$\left[\operatorname{Re}^{I}\left(\boldsymbol{L}^{\text {tri }}\right)(\mathrm{CO})_{3} \mathrm{Br}\right]$} \\
\hline \multicolumn{4}{|c|}{ Intramolecular Pi-Pi interactions } \\
\hline $\operatorname{Tri}_{\text {centroid }} \cdots \mathrm{Ph}_{\text {centroid }}(\AA)$ & 3.573 & 3.637 & 3.593 \\
\hline $\mathrm{C}(4) \cdots \mathrm{C}(8)(\AA)^{a}$ & $3.19(2)$ & $3.20(1)$ & $3.20(2)$ \\
\hline $\mathrm{C}(4){ }^{\cdots} \mathrm{C}(9)(\AA)^{a}$ & $3.18(2)$ & $3.46(1)$ & $3.18(2)$ \\
\hline \multicolumn{4}{|c|}{ Intermolecular Pi-Pi interactions } \\
\hline $\mathrm{Ph}_{\text {centroid }} \cdots{ }$ Tri $_{\text {centroid }}(\AA)$ & 3.955 & 3.884 & - \\
\hline $\mathrm{C}(6)-\mathrm{C}(8 \mathrm{~B})(\AA)^{a}$ & $3.36(2)$ & $3.40(1)$ & - \\
\hline $\mathrm{C}(1)-\mathrm{C}(9 \mathrm{~B})(\AA)^{a}$ & $3.36(2)$ & $3.35(1)$ & - \\
\hline \multicolumn{4}{|c|}{ Intermolecular H-bonding } \\
\hline $\mathrm{C}(11)-\mathrm{H} \cdots \mathrm{O}(1 \mathrm{~A})(\AA)$ & $3.40(2)$ & $3.65(1)$ & $3.40(2)$ \\
\hline$>\mathrm{C}(11)-\mathrm{H} \cdots \mathrm{O}(1 \mathrm{~A})\left(^{\circ}\right)$ & 175.6 & 162.5 & 174.0 \\
\hline $\mathrm{C}(9)-\mathrm{H} \cdots \mathrm{O}(1 \mathrm{~A})(\AA)$ & $3.36(2)$ & $3.35(1)$ & $3.34(2)$ \\
\hline$>\mathrm{C}(11)-\mathrm{H} \cdots \mathrm{O}(1 \mathrm{~A})\left(^{\circ}\right)$ & 161.4 & 153.5 & 159.7 \\
\hline
\end{tabular}

${ }^{a}$ Closest contacts 


\section{Supplementary Structural Figures}

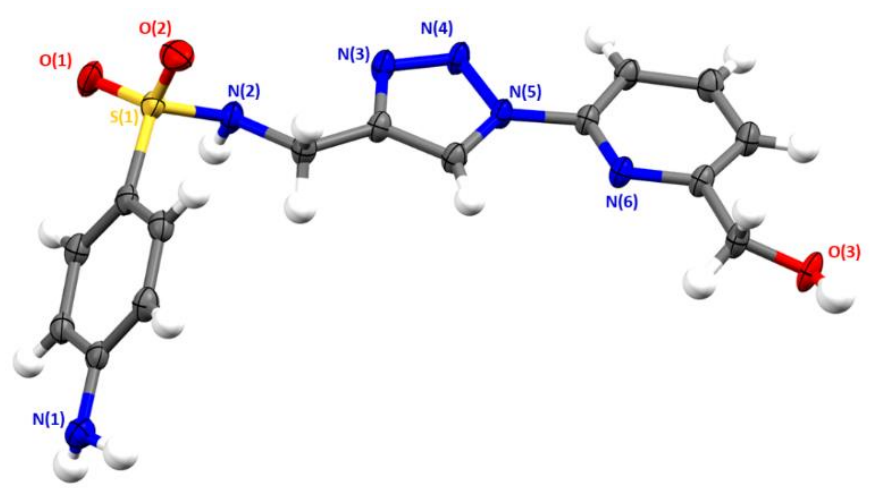

Figure S24. Solid state structure of $\mathbf{L}^{\text {tri }} \mathrm{OH}$. Thermal elipsoids are shown at the $50 \%$ probability level.

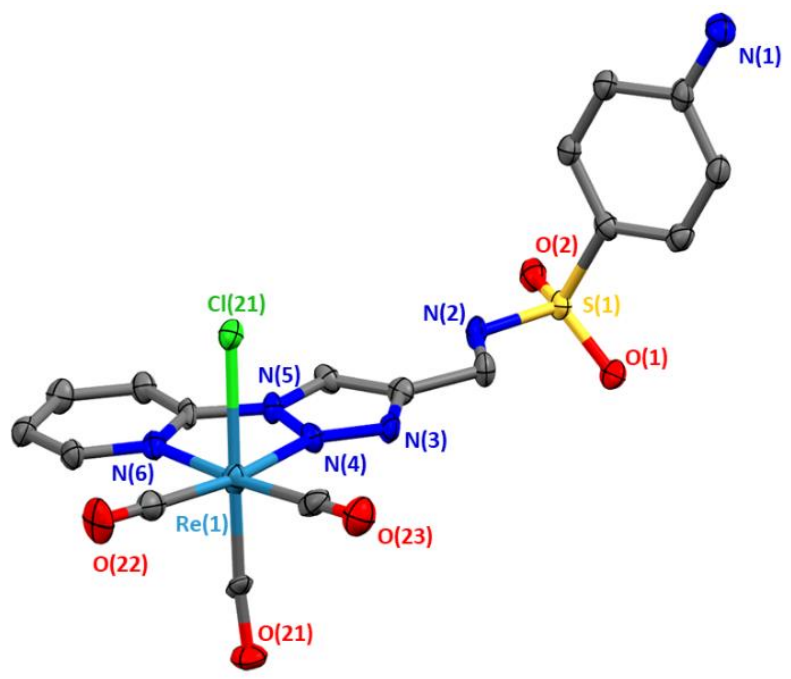

Figure S25. Solid state structure of $\left[\operatorname{Re}^{\prime}\left(\mathrm{L}^{\text {tri }}\right)(\mathrm{CO})_{3} \mathrm{Cl}\right]$, showing only the major component of $\mathrm{CO} / \mathrm{Cl}$ disorder. $\mathrm{H}$-atoms and solvent molecules have been omitted for clarity. Thermal ellipsoids are shown at the 50\% probability level.

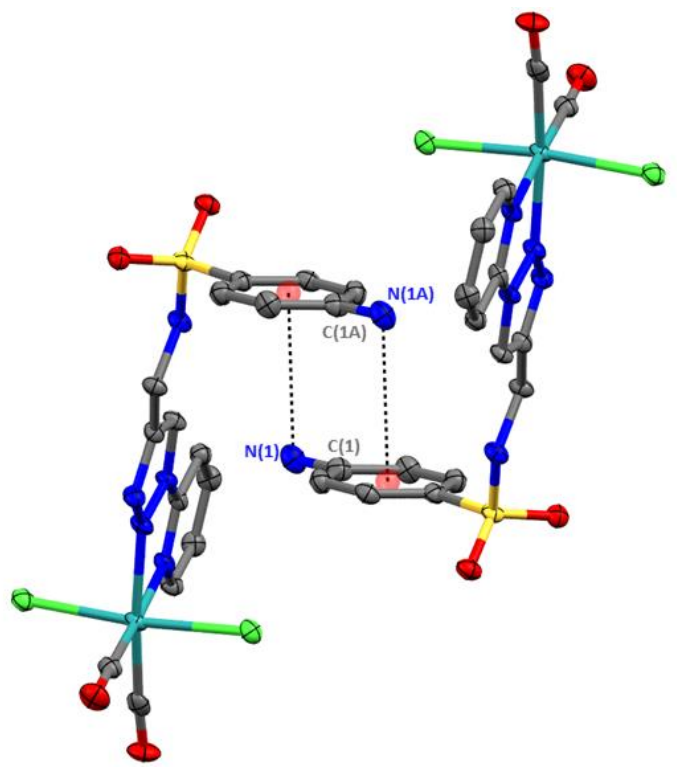

Figure S26. Reciprocated aniline-aniline interactions observed for the extended complexes, shown here for $\left[\mathrm{Ru}(\underline{\underline{\mathrm{L}} \text { tri }})(\mathrm{CO})_{2} \mathrm{Cl} \mathrm{L}_{2}\right]$ as an example. Solvent molecules and $\mathrm{H}$-atoms have been omitted for clarity. Thermal ellipsoids are shown at the $50 \%$ probability level. 


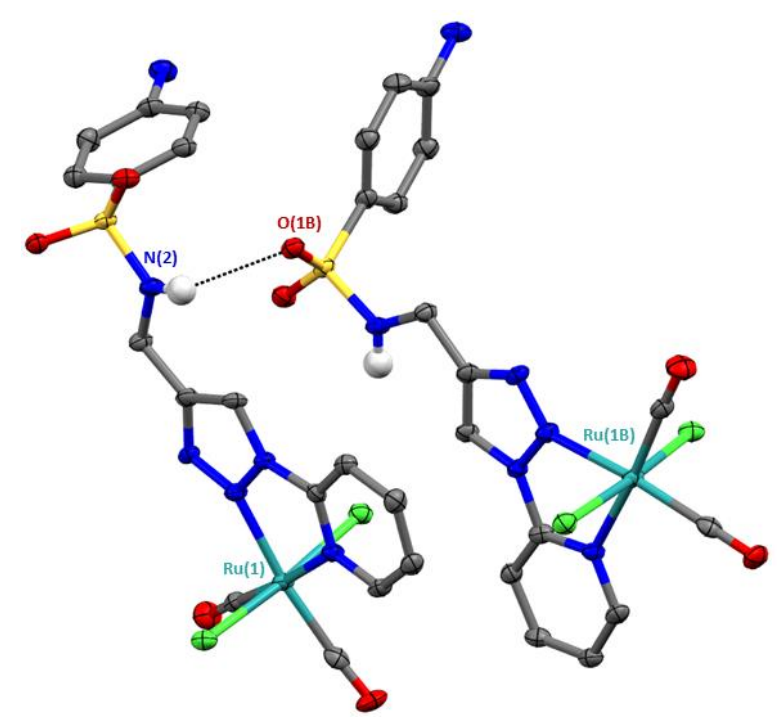

Figure S27. $\mathrm{N}(2)-\mathrm{H} \cdots \mathrm{O}(1) \mathrm{H}$-bonding observed for the extended complexes, shown here for $\left[\mathrm{Ru}(\underline{\mathrm{L} \text { tri }})\left(\mathrm{CO}_{2} \mathrm{Cl}_{2}\right]\right.$ as an example. Solvent molecules and $\mathrm{H}$-atoms, except for those involved in this $\mathrm{H}$-bond, have been omitted for clarity. Thermal ellipsoids are shown at the $50 \%$ probability level.

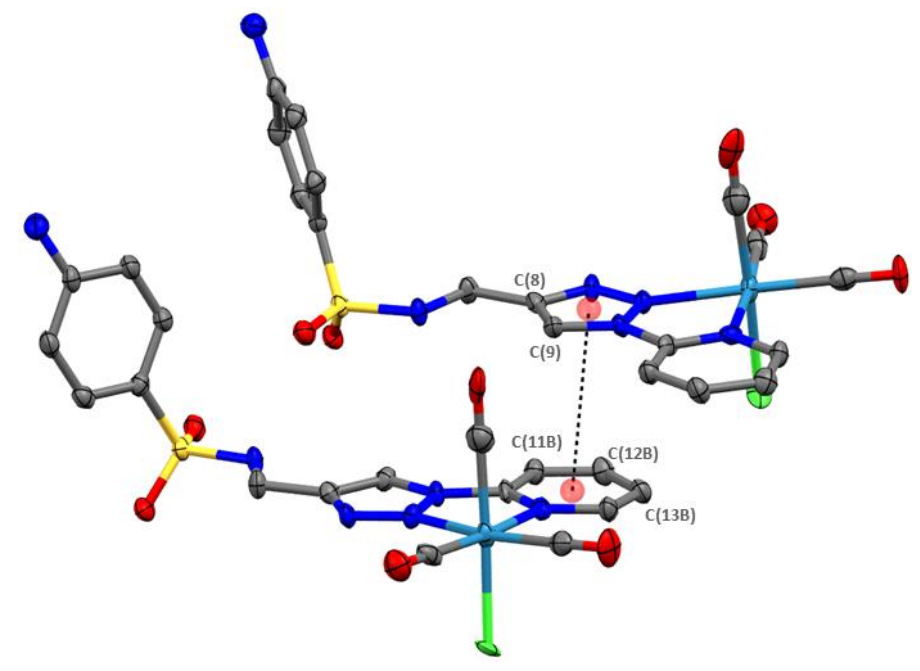

Figure S28. Intermolecular pi-stacking observed for the extended complexes, shown here for $\left[\operatorname{Re}\left(\underline{\underline{L^{t r i}}}\right)(\mathrm{CO})_{3} \mathrm{Cl}\right]$ as an example. Solvent molecules and $\mathrm{H}$-atoms have been omitted for clarity. Only the major component of main residue disorder is shown for clarity. Thermal ellipsoids are shown at the $50 \%$ probability level.

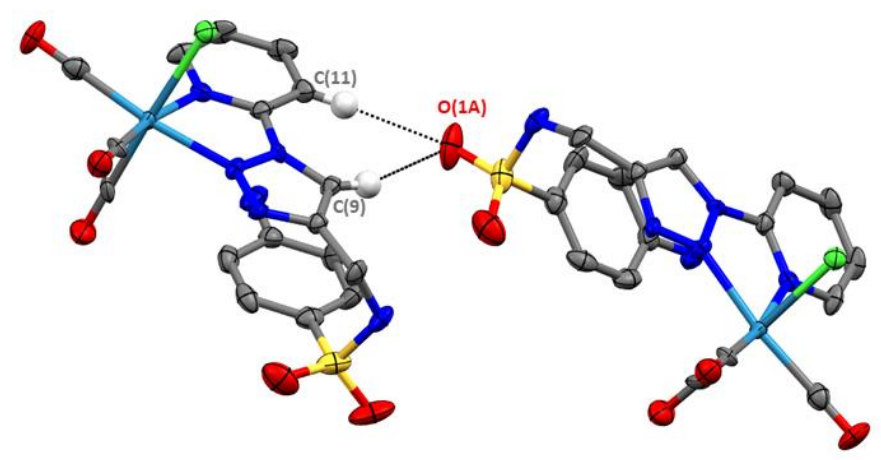

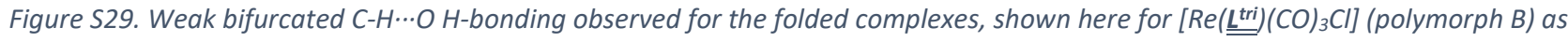
an example. Solvent molecules and $\mathrm{H}$-atoms, except for those involved in this $\mathrm{H}$-bonding, have been omitted for clarity. Thermal ellipsoids are shown at the $50 \%$ probability level. 


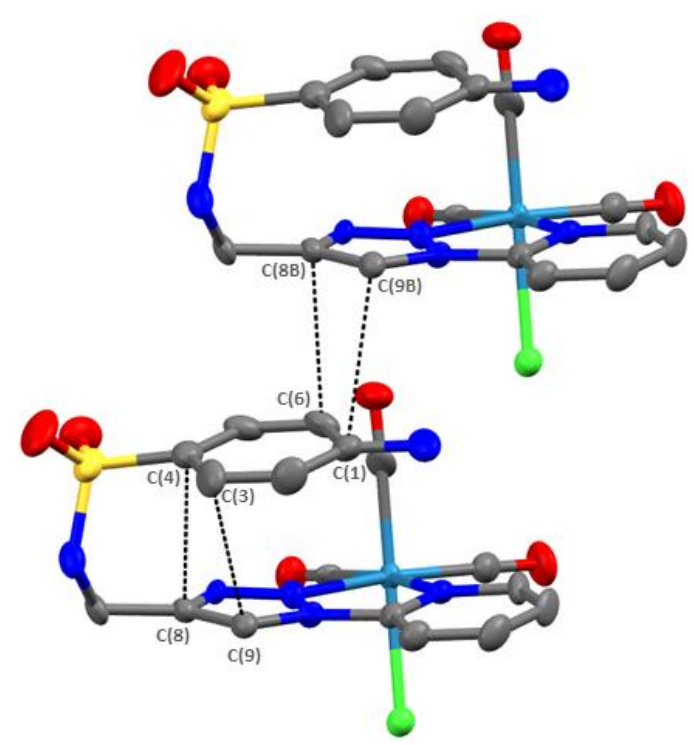

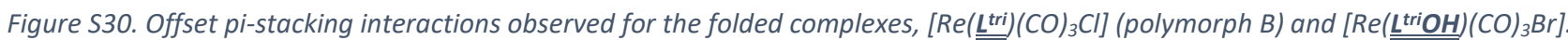
Solvent molecules and H-atoms have been omitted for clarity. Thermal ellipsoids are shown at the 50\% probability level.

\section{Supplementary Photophysical Data}

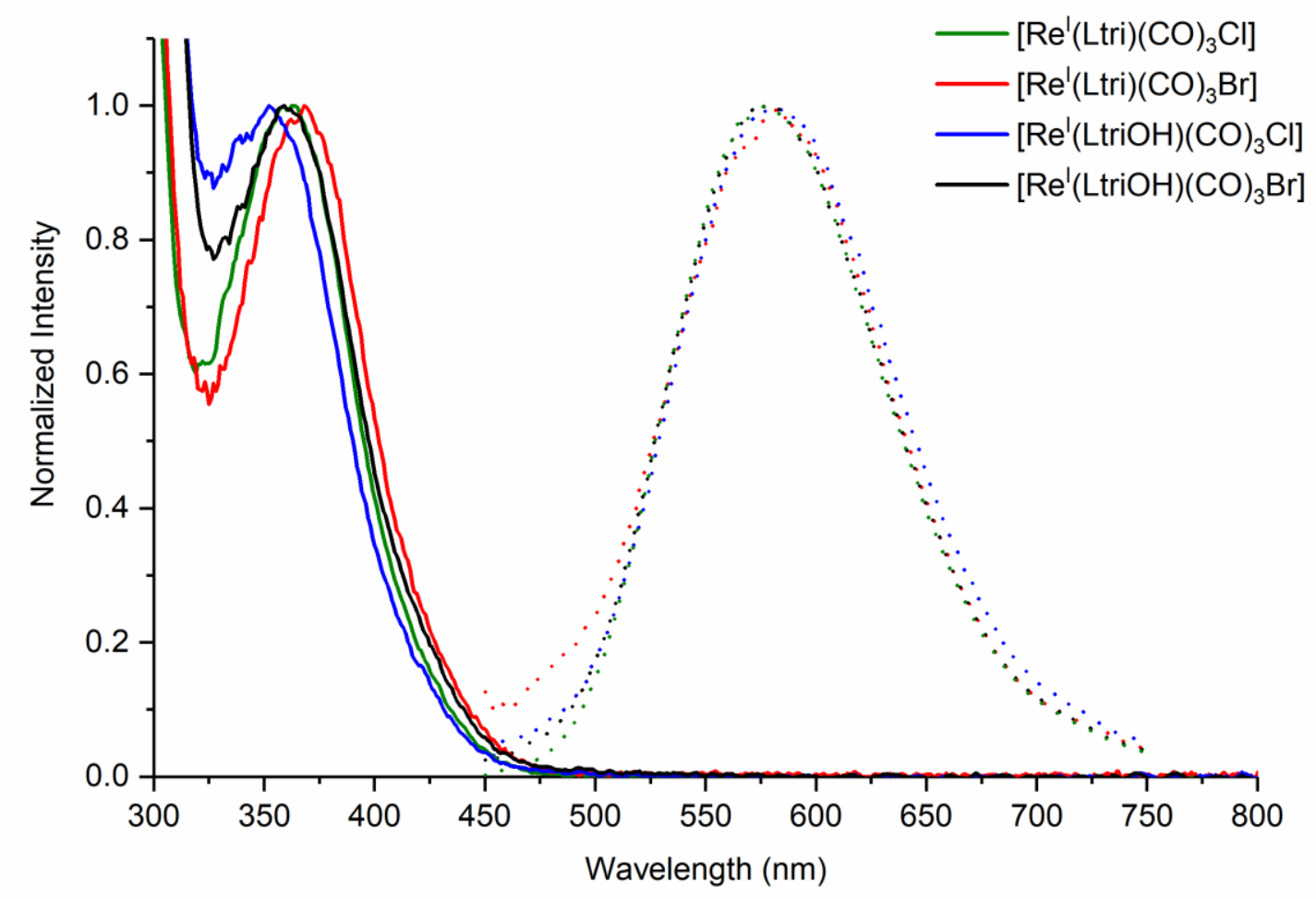

Figure S31. Normalized absorption (solid lines) and photoluminescence (dashed lines) data for ethanolic solutions (0.025-0.05 mmol L1) of the Rhenium carbonyl complexes reported in this work. 


\section{Supplementary Ligand Release Data}
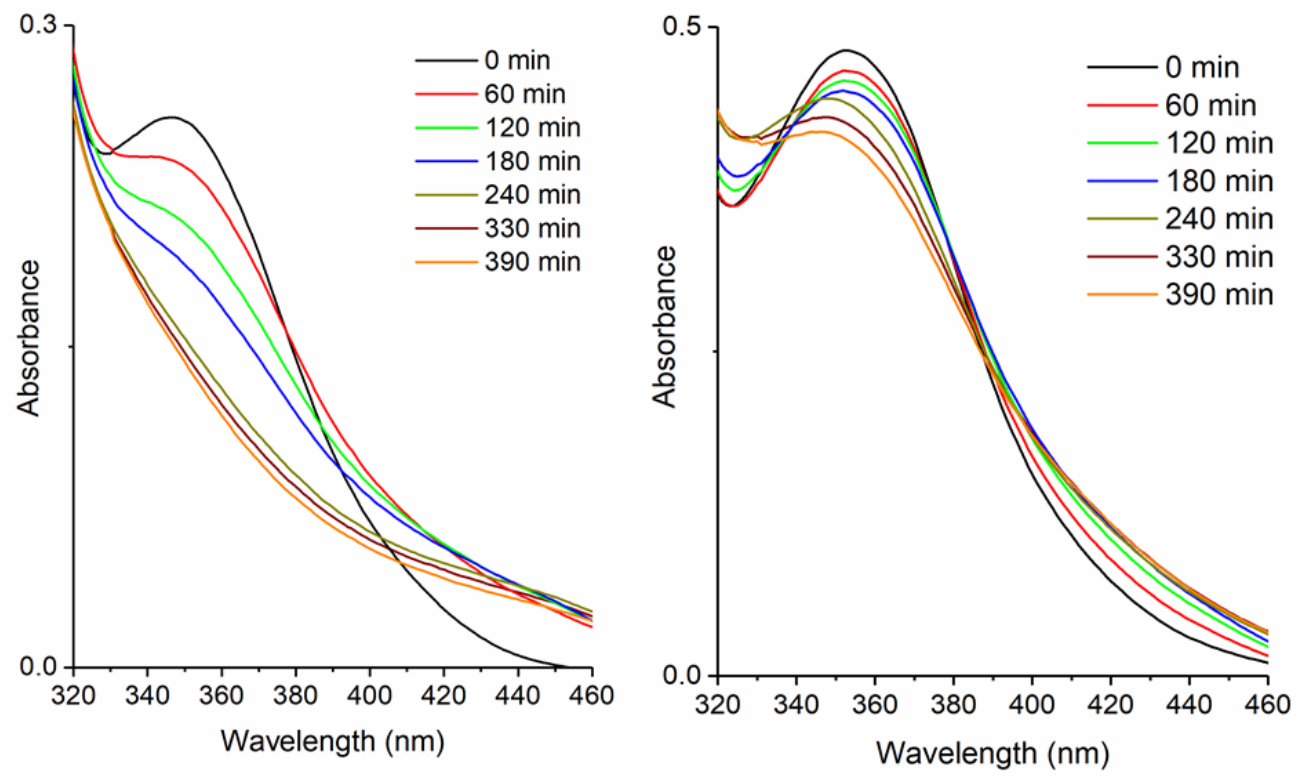

Figure S32. Progression of the $360 \mathrm{~nm}$ absorption band for a solution of $\left[\operatorname{Re}^{\prime}\left(\mathrm{L}^{\text {tri } \mathrm{OH}}\right)(\mathrm{CO})_{3} \mathrm{Cl}\right](\mathrm{left})\left[\operatorname{Re}^{\prime}\left(\mathrm{L}^{\text {tri }}\right)(\mathrm{CO}){ }_{3} \mathrm{Cl}\right]($ right $)$ in DMSO with time under irradiation of $265 \mathrm{~nm}$ light.

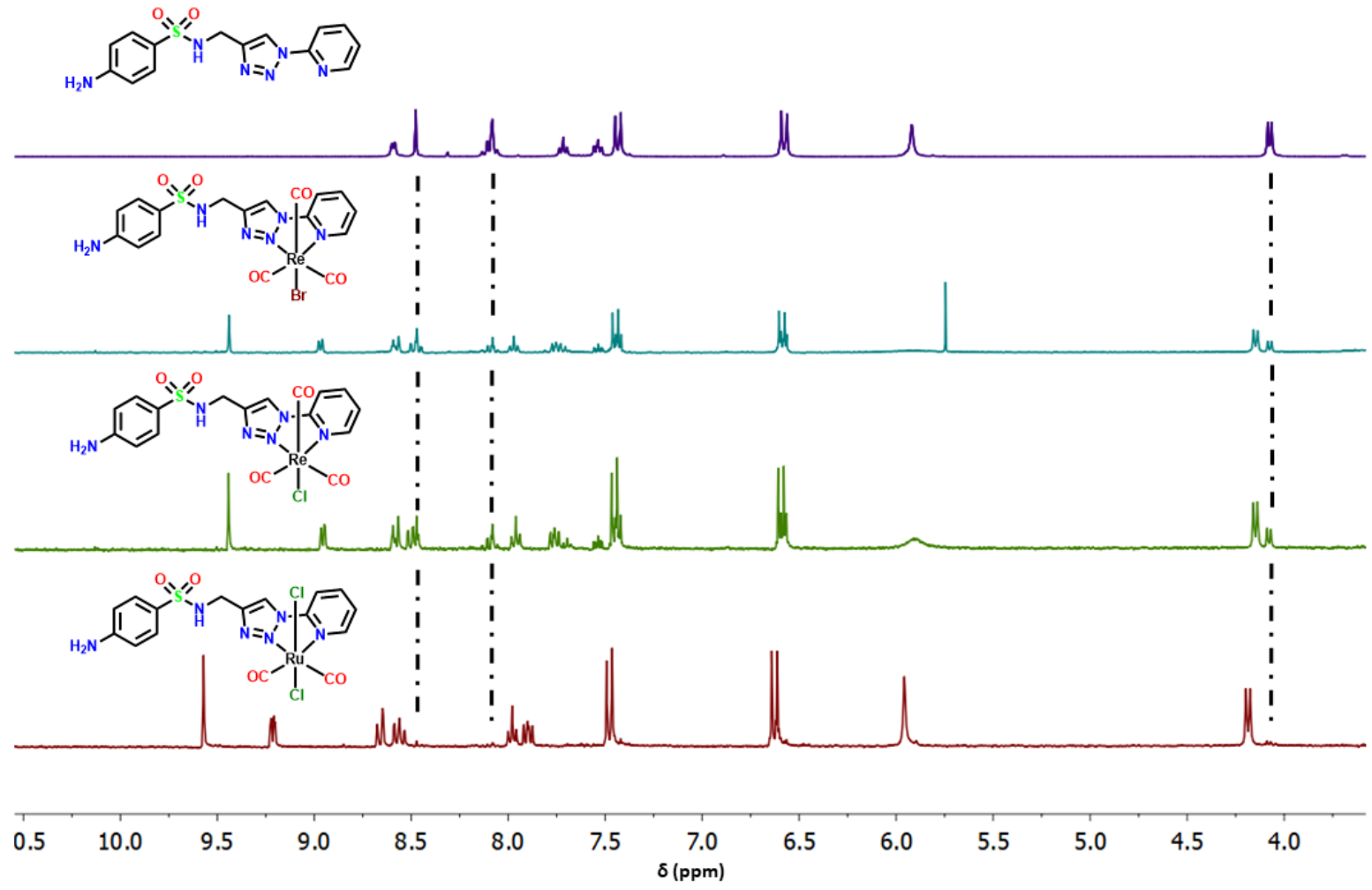

Figure S33. Comparison of the ${ }^{1} \mathrm{H} N \mathrm{NR}$ spectra of partially decomposed samples of $\left[\operatorname{Re}^{\prime}\left(\mathrm{L}^{\text {tri }}\right)(\mathrm{CO})_{3} \mathrm{Br}\right],\left[\operatorname{Re}^{\prime}\left(\mathrm{L}^{\text {tri }}\right)(\mathrm{CO})_{3} \mathrm{Cl}\right]$ and $\left[R u^{\prime \prime}\left(L^{\text {tri }}\right)(\mathrm{CO})_{2} \mathrm{Cl}\right]$ with the corresponding free ligand $\mathbf{L}^{\text {tri. }}$. The vertical dashed lines indicate the appearance of characteristic peaks corresponding to the free ligand $L^{\text {tri }}$. The spectra were recorded at $300 \mathrm{MHz}$ (metal complexes) or $200 \mathrm{MHz}$ (L ${ }^{\text {tri }}$ ) in d6-DMSO. 


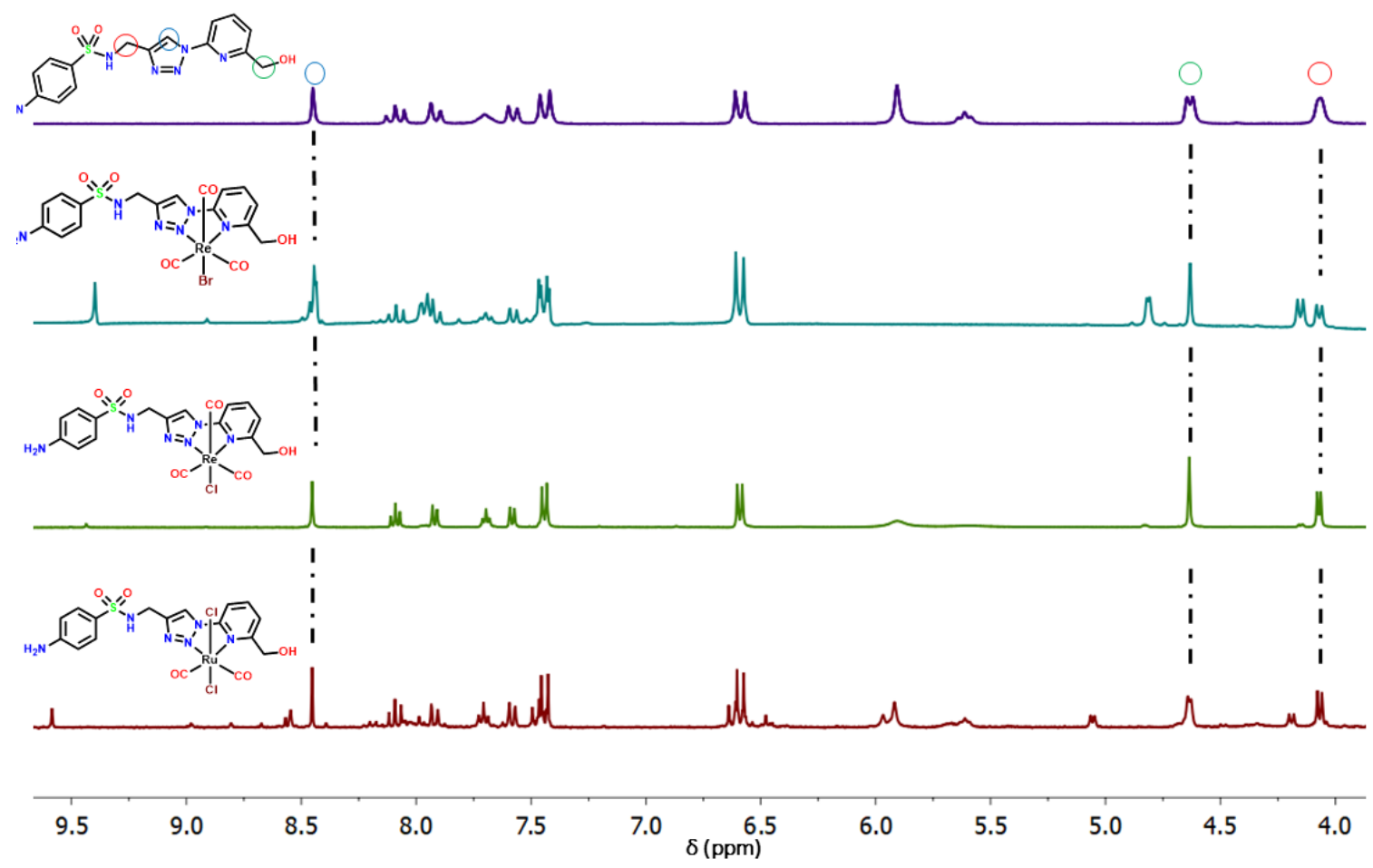

Figure S34. Comparison of partial ${ }^{1} \mathrm{H} N \mathrm{NR}$ spectra of partially decomposed samples of $\left[\operatorname{Re}^{\prime}\left(\mathrm{LrriOH}^{\text {tri }}(\mathrm{CO})_{3} \mathrm{Br}\right],\left[\operatorname{Re}^{\prime}\left(\mathrm{L}^{\text {tri }} \mathrm{OH}\right)(\mathrm{CO})_{3} \mathrm{Cl}\right]\right.$ and $\left[R u^{\prime \prime}\left(L^{\text {tri }} \mathrm{OH}\right)(\mathrm{CO})_{2} \mathrm{Cl}_{2}\right]$ with the corresponding free ligand $\mathbf{L}^{\text {tri }} \mathrm{OH}$. The vertical dashed lines indicate the appearance of characteristic peaks corresponding to the free ligand $\mathbf{L}^{\text {tri }} \mathrm{OH}$. The spectra were recorded at $300 \mathrm{MHz}$ (metal complexes) or $200 \mathrm{MHz}$ ( $\mathrm{L}^{\text {tri }} \mathrm{OH}$ ) in $\mathrm{d} 6$ DMSO.

\section{$\left[\mathrm{Ru}\left(\mathrm{Ltri}^{\mathrm{tr}}\right)(\mathrm{CO})_{2} \mathrm{Cl}_{2}\right]$}

As Prepared

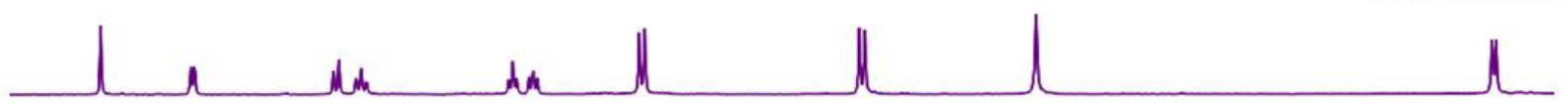

$24 \mathrm{~h}$

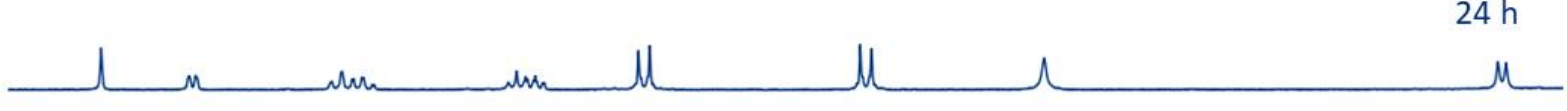

$48 \mathrm{~h}$

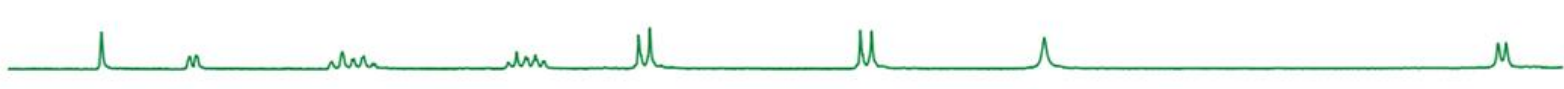

1 week
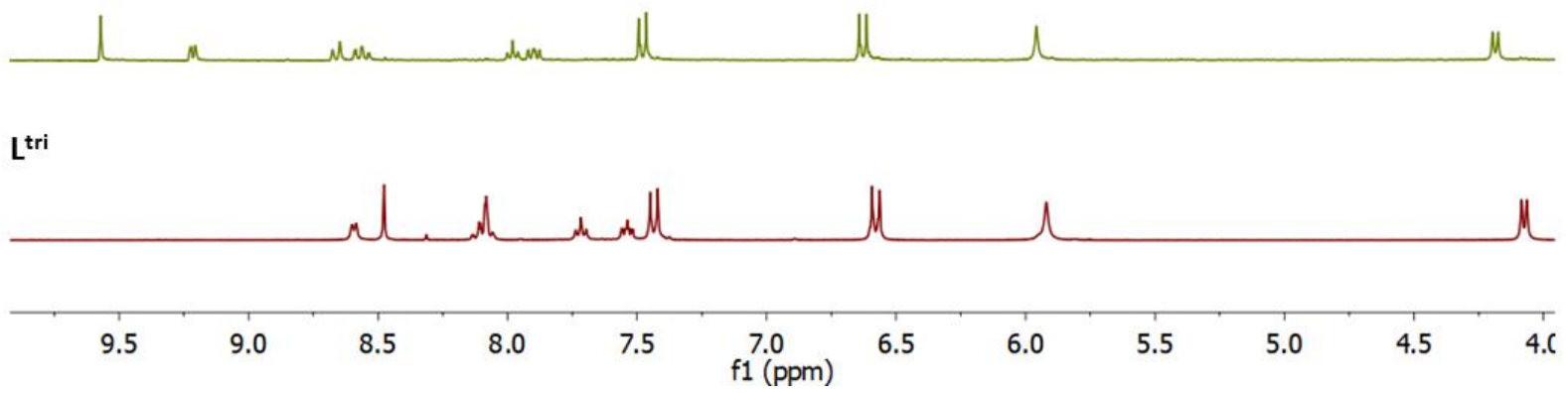

Figure S35. Stacked partial ${ }^{1} \mathrm{H}$ NMR spectra (d6-DMSO) of a solution of $\left[R u^{\prime \prime}\left(\mathrm{L}^{\text {tri }}\right)(\mathrm{CO})_{2} \mathrm{Cl}_{2}\right]$ as prepared, after 24 hours, 48 hours and 1 week in d6-DMSO, as well as the corresponding free ligand Ltri in d6-DMSO. 

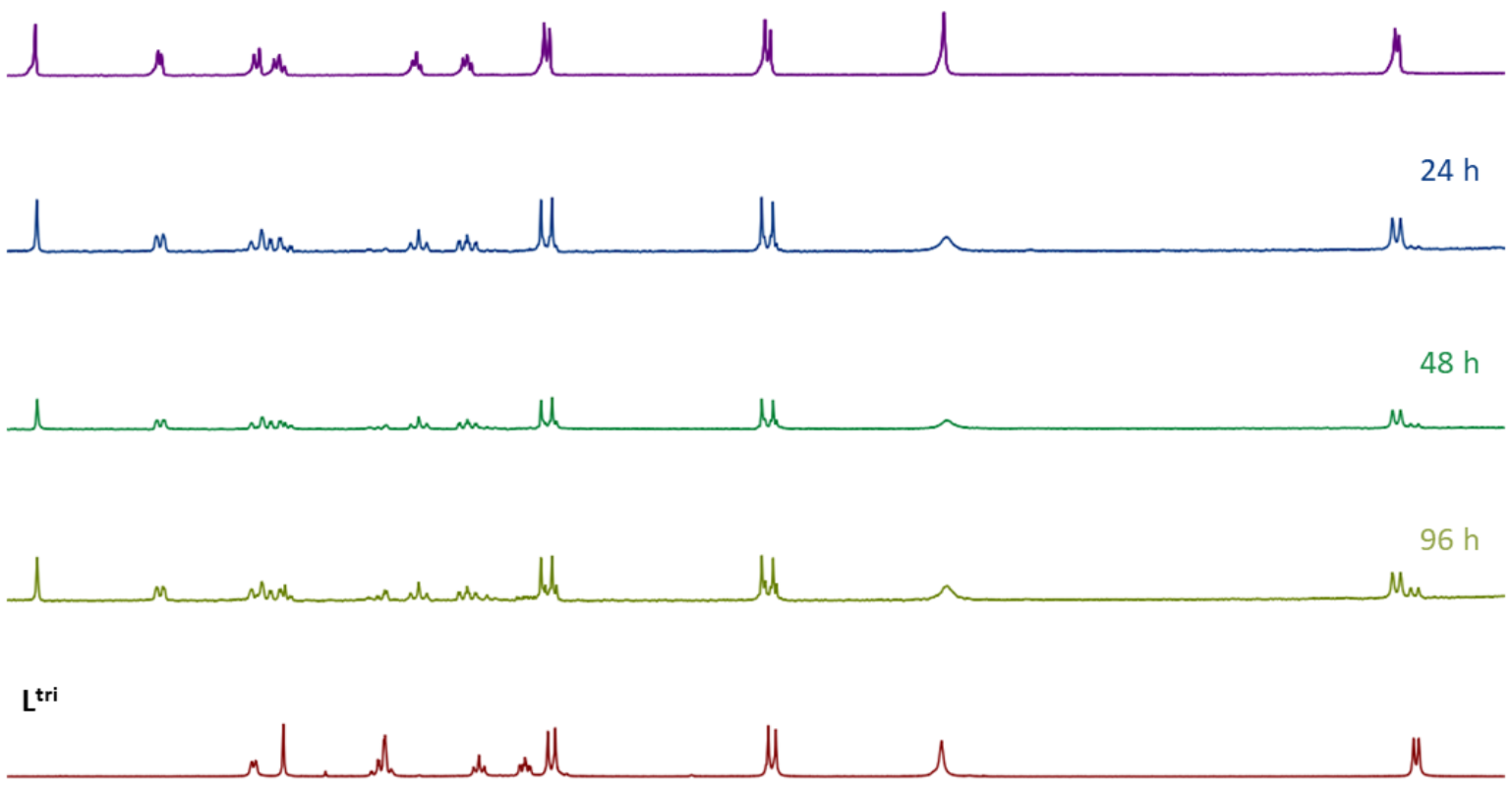

$\begin{array}{lllllllllllllllllllllllllllll}9.4 & 9.2 & 9.0 & 8.8 & 8.6 & 8.4 & 8.2 & 8.0 & 7.8 & 7.6 & 7.4 & 7.2 & 7.0 & 6.8 & 6.6 & 6.4 & 6.2 & 6.0 & 5.8 & 5.6 & 5.4 & 5.2 & 5.0 & 4.8 & 4.6 & 4.4 & 4.2 & 4.0 & 3.8\end{array}$ $\mathrm{f1}(\mathrm{ppm})$

Figure S36. Stacked partial ${ }^{1} \mathrm{H}$ NMR spectra (d6-DMSO) of a solution of $\left[\operatorname{Re}^{\prime}\left(\mathrm{L}^{\text {tri }}\right)(\mathrm{CO}){ }_{3} \mathrm{Cl}\right]$ as prepared, after 24 hours, 48 hours and 96 hours in d6-DMSO, as well as the corresponding free ligand $\mathbf{L}^{\text {tri }}$ in d6-DMSO.

\section{$\left[\operatorname{Re}\left(\mathrm{L}^{\mathrm{tri}}\right)(\mathrm{CO})_{3} \mathrm{Br}\right]$}
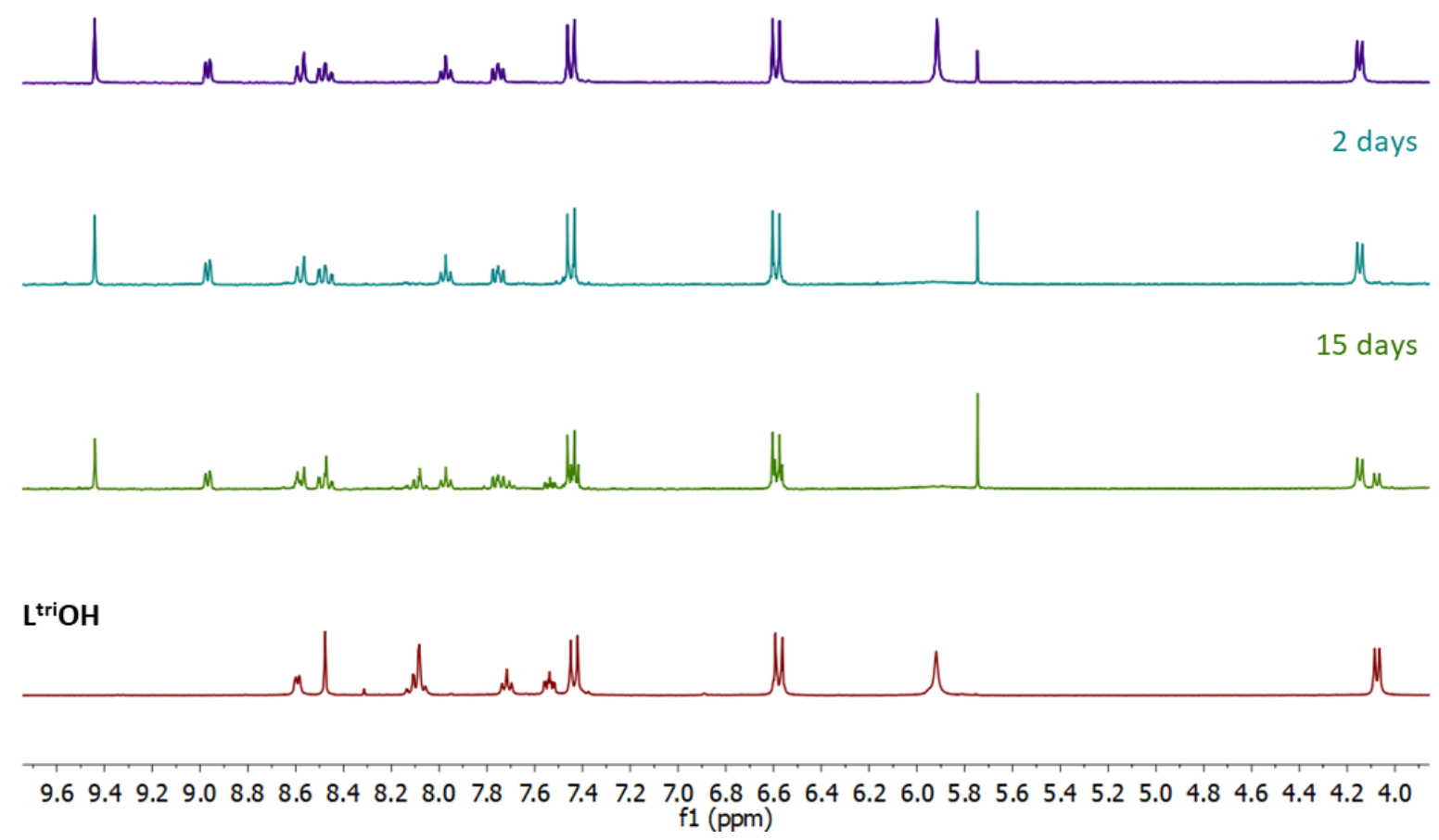

Figure S37. Stacked partial ${ }^{1} \mathrm{H}$ NMR spectra (d6-DMSO) of a solution of $\left[\operatorname{Re}^{\prime}\left(\mathrm{L}^{\text {tri }}\right)(\mathrm{CO})_{3} \mathrm{Br}\right]$ as prepared, after 2 days and 15 days in d6DMSO, as well as the corresponding free ligand $\mathbf{L}^{\text {tri }}$ in $\mathbf{6 6 - D M S O}$. 

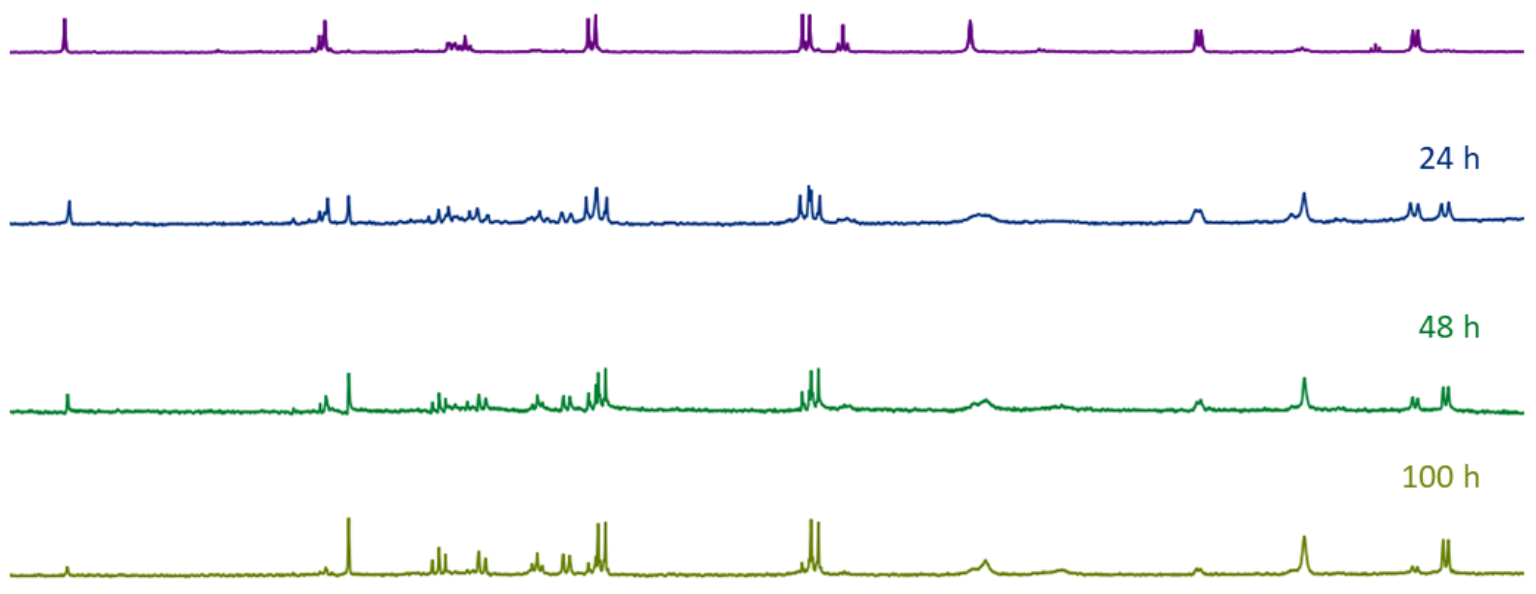

\section{LtriOH}

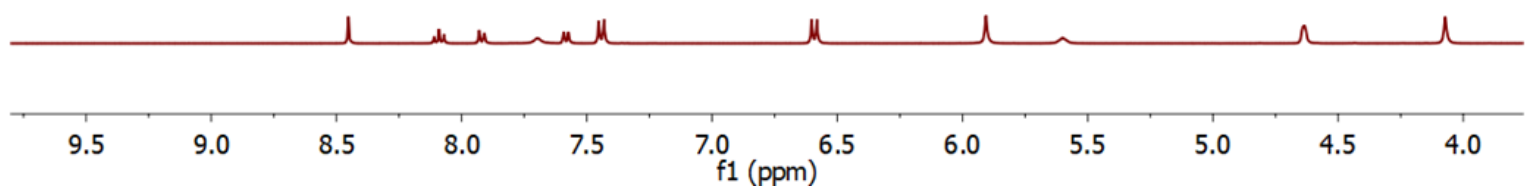

Figure S38. Stacked partial ${ }^{1} \mathrm{H}$ NMR spectra (d6-DMSO) of a solution of $\left[\mathrm{Ru} u^{\prime \prime}\left(\mathrm{L}^{\text {triOH}} \mathrm{OH}\right)(\mathrm{CO})_{2} \mathrm{Cl}_{2}\right]$ as prepared, after 24 hours, 48 hours and 100 hours in d6-DMSO, as well as the corresponding free ligand $\mathbf{L}^{\text {tri }}$ in d6-DMSO.

\section{$\left[\operatorname{Re}\left(\mathrm{L}^{\text {triOH}}\right)(\mathrm{CO})_{3} \mathrm{Cl}\right]$}
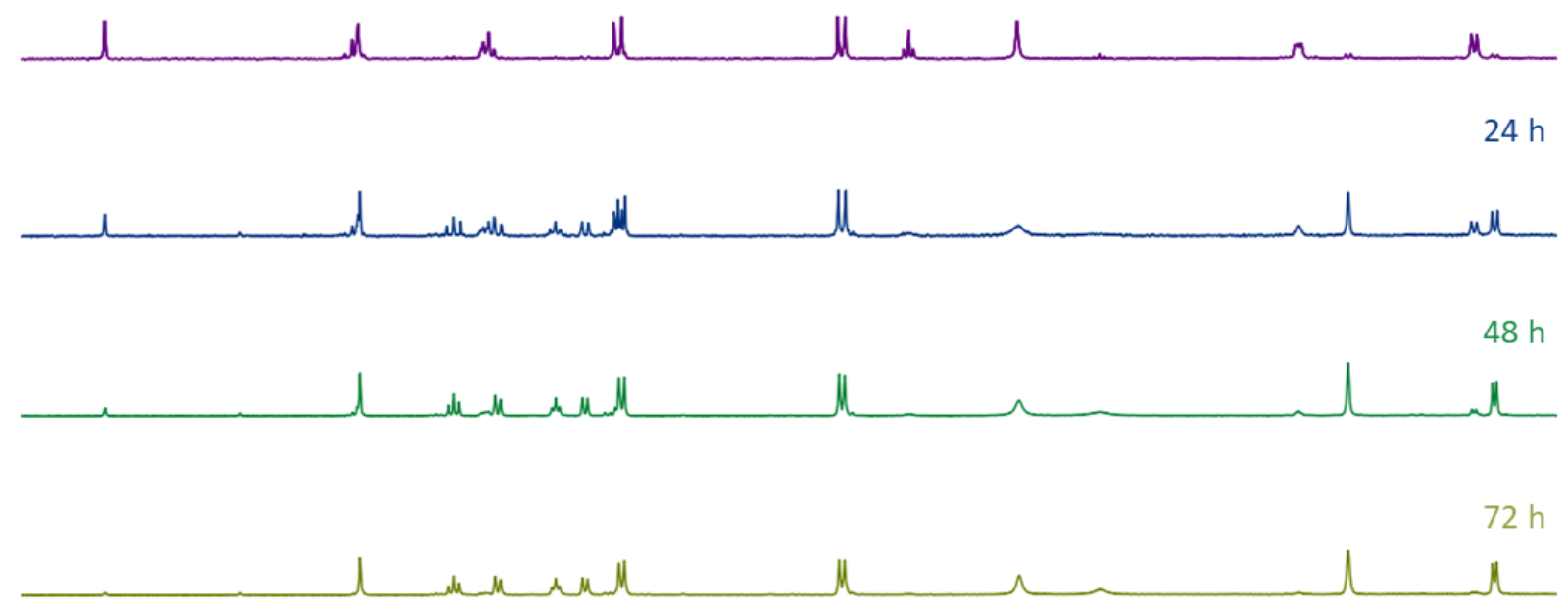

\section{$\mathrm{L}^{\text {tri } \mathrm{OH}}$}

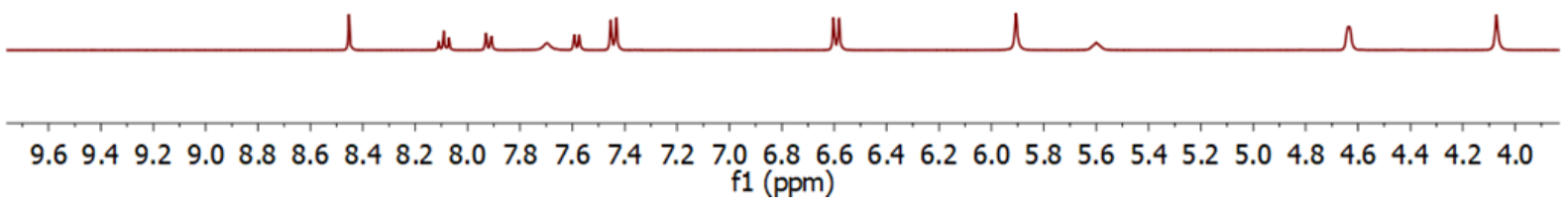

Figure S39. Stacked partial ${ }^{1} \mathrm{H}$ NMR spectra (d6-DMSO) of a solution of $\left[\operatorname{Re}^{\prime}\left(\mathrm{L}^{\text {tri }} \mathrm{OH}\right)(\mathrm{CO}){ }_{3} \mathrm{Cl}\right]$ as prepared, after 24 hours, 72 hours and 100 hours in d6-DMSO, as well as the corresponding free ligand $L^{\text {tri }}$ in d6-DMSO. 

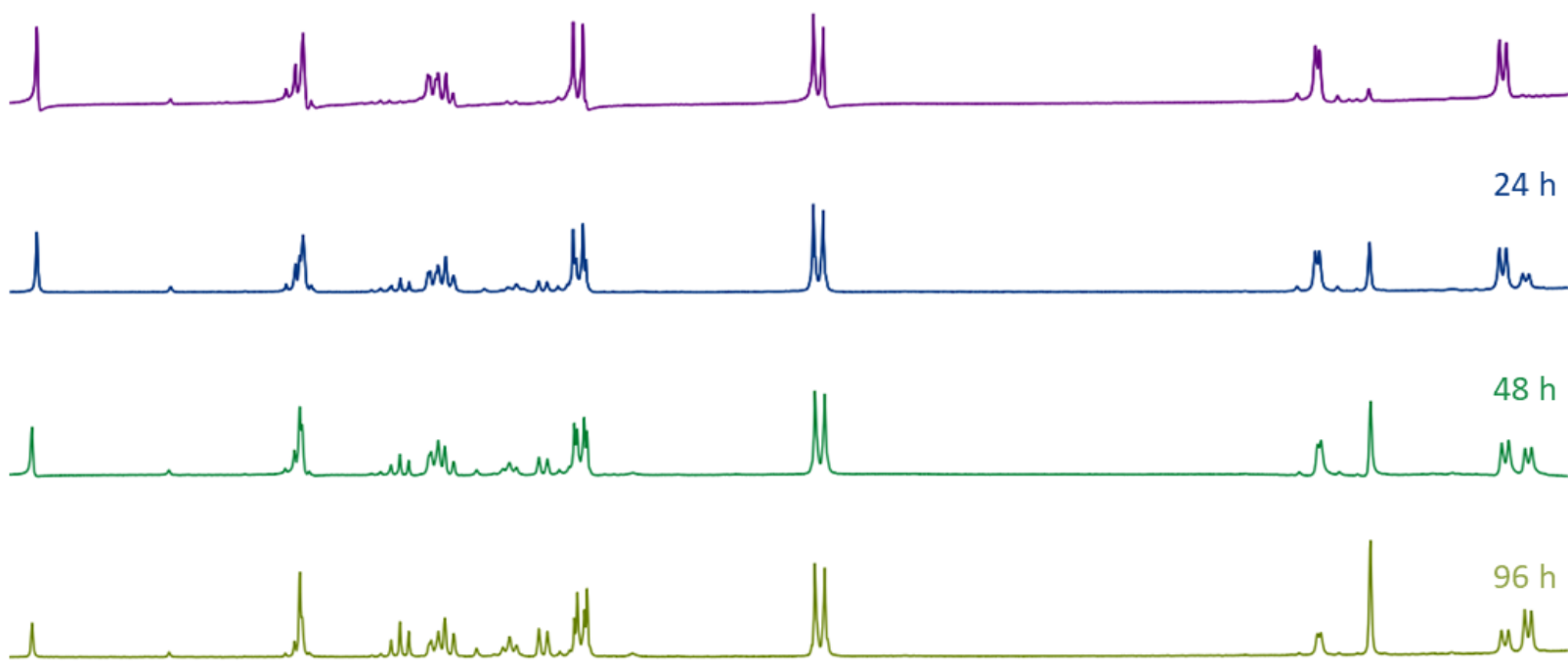

LtriOH

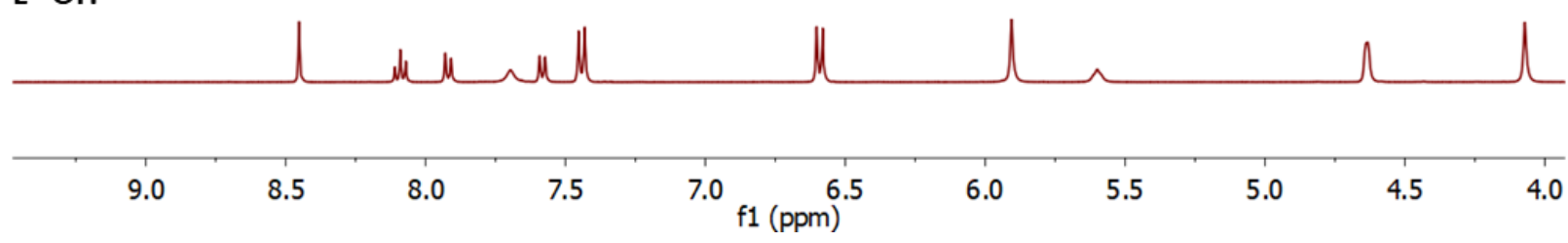

Figure S40. Stacked partial ${ }^{1} \mathrm{H}$ NMR spectra (d6-DMSO) of a solution of [Re'( (LtriOH)(CO) 3 Br] as prepared, after 24 hours, 72 hours and 100 hours in d6-DMSO, as well as the corresponding free ligand $\mathbf{L}^{\text {tri }}$ in d6-DMSO.

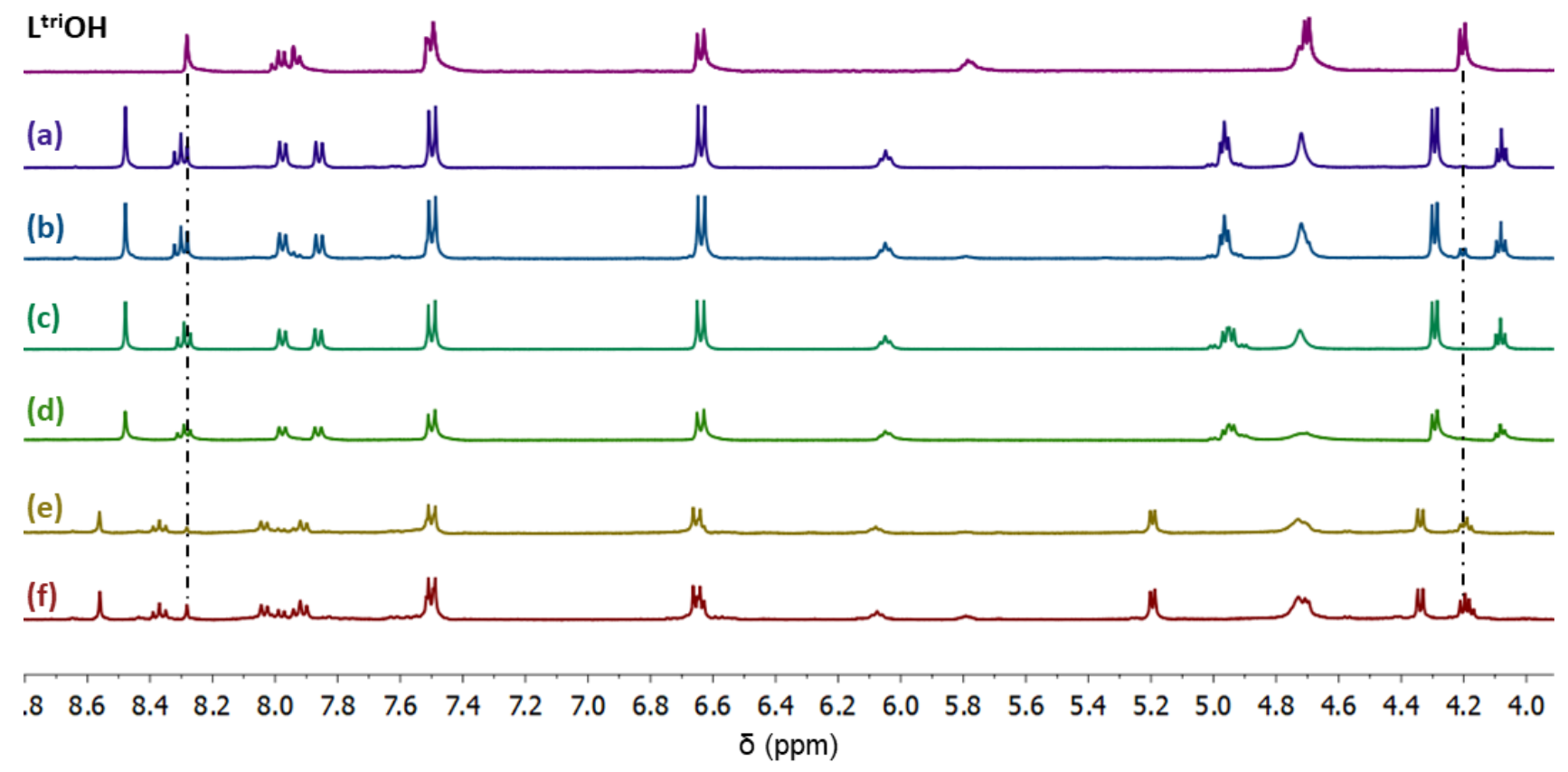

Figure S41. Stacked partial ${ }^{1} \mathrm{H}$ NMR spectra (d3-MeCN) of solutions of: free ligand $\mathbf{L}^{\text {tri }} \mathrm{OH},\left[\operatorname{Re}^{\prime}\left(\mathbf{L}^{\text {tri } O H}\right)(\mathrm{CO}){ }_{3} \mathrm{Cl}\right]$ as prepared (a) and after

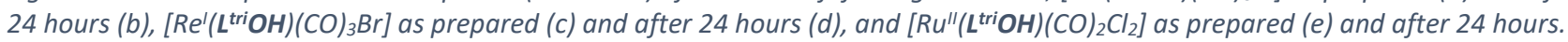
Please note that the both $\mathrm{L}^{\text {tri }} \mathrm{OH}$ and $\left[\mathrm{Ru} u^{\prime \prime}\left(\mathrm{L}^{\text {tri }} \mathrm{OH}\right)(\mathrm{CO})_{2} \mathrm{Cl}_{2}\right]$ are only sparingly soluble in this solvent resulting in the poor resolution of these spectra observed here. 
Table S5. Percentage ligand release from the rhenium(I) and ruthenium(II) complexes in this work after storage for 24 and 48 hours in a d6-DMSO solution in the dark. Values obtained by ${ }^{1} \mathrm{H}$ NMR integration.

\begin{tabular}{|l|l|l|}
\hline Complex & 24 hours & 48 hours \\
\hline$\left[\operatorname{Ru}^{\prime \prime}\left(\mathrm{L}^{\text {tri }}\right)(\mathrm{CO})_{2} \mathrm{Cl}_{2}\right]$ & $>5 \%$ & $>5 \%$ \\
\hline$\left[\operatorname{Re}^{\prime}\left(\mathrm{L}^{\text {tri }}\right)(\mathrm{CO})_{3} \mathrm{Cl}\right]$ & $>5 \%$ & $c a .5 \%$ \\
\hline$\left[\operatorname{Re}^{\prime}\left(\mathrm{L}^{\text {tri }}\right)(\mathrm{CO})_{3} \mathrm{Br}\right]$ & $>5 \%$ & $>5 \%$ \\
\hline$\left[\operatorname{Ru}^{\prime \prime}\left(\mathrm{L}^{\text {tri }} \mathrm{OH}\right)(\mathrm{CO})_{2} \mathrm{Cl}_{2}\right]$ & $50 \%$ & $76 \%$ \\
\hline$\left[\operatorname{Re}^{\prime}\left(\mathrm{L}^{\text {tri }} \mathrm{OH}\right)(\mathrm{CO})_{3} \mathrm{Cl}\right]$ & $62 \%$ & $80 \%$ \\
\hline$\left[\operatorname{Re}^{\prime}\left(\mathrm{L}^{\text {tri }} \mathrm{OH}\right)(\mathrm{CO})_{3} \mathrm{Br}\right]$ & $35 \%$ & $45 \%$ \\
\hline
\end{tabular}




\section{IR Spectroscopy}

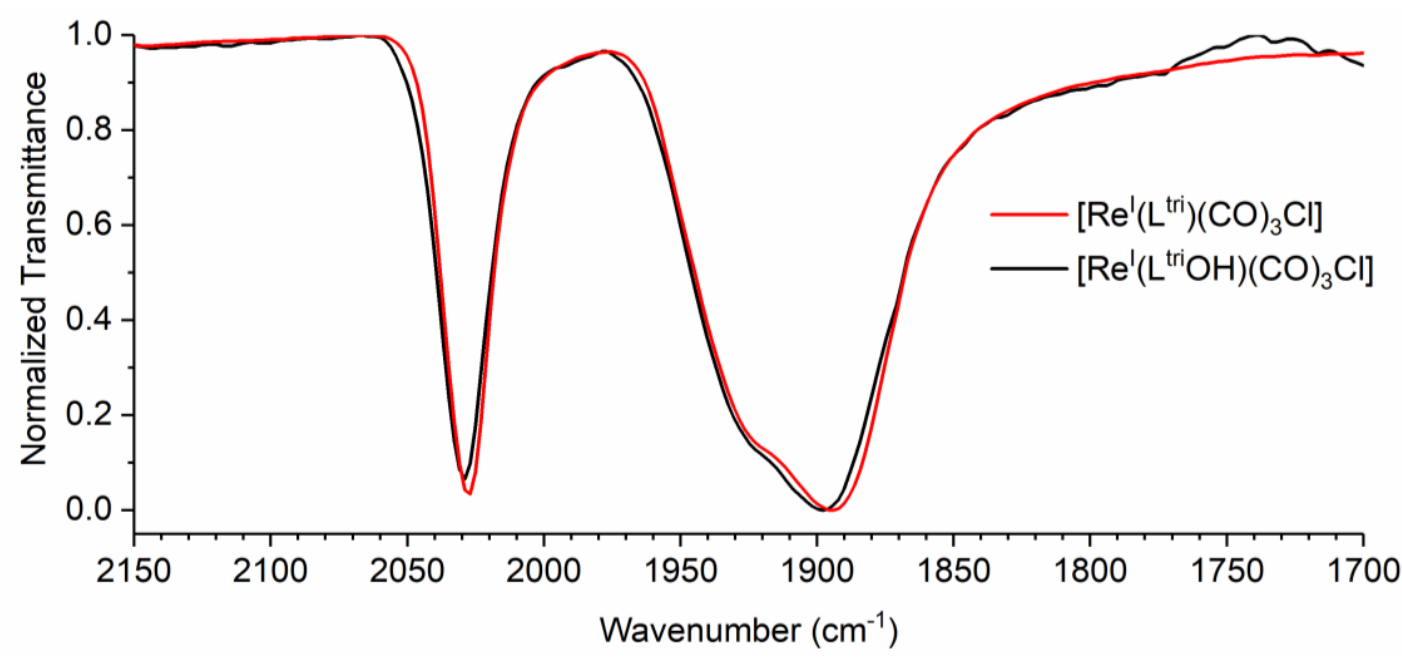

Figure S42. Comparison of the $\mathrm{CO}$ stretching bands in the ATR-IR spectrum of the complexes $\left[\operatorname{Re}^{\prime}\left(\mathrm{L}^{\text {tri }}\right)(\mathrm{CO})_{3} \mathrm{Cl}\right]$ and $\left[\operatorname{Re}^{\prime}\left(\mathrm{L}^{\text {tri }} \mathrm{OH}\right)(\mathrm{CO}){ }_{3} \mathrm{Cl}\right]$.

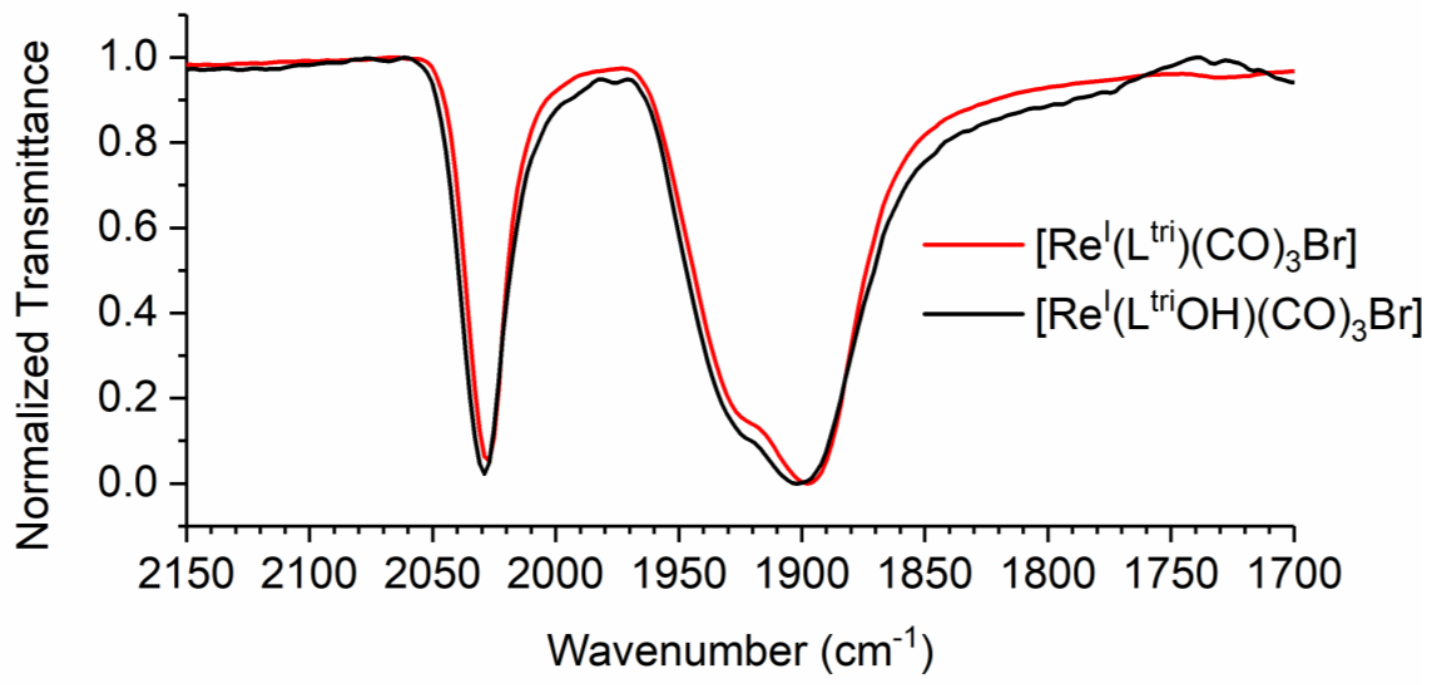

Figure S43. Comparison of the CO stretching bands in the ATR-IR spectrum of the complexes $\left[\operatorname{Re}^{\prime}\left(\mathrm{L}^{\text {tri }}\right)(\mathrm{CO})_{3} \mathrm{Br}\right]$ and $\left[\operatorname{Re}^{\prime}\left(\mathrm{L}^{\text {tri }} \mathrm{OH}\right)(\mathrm{CO})_{3} \mathrm{Br}\right]$.

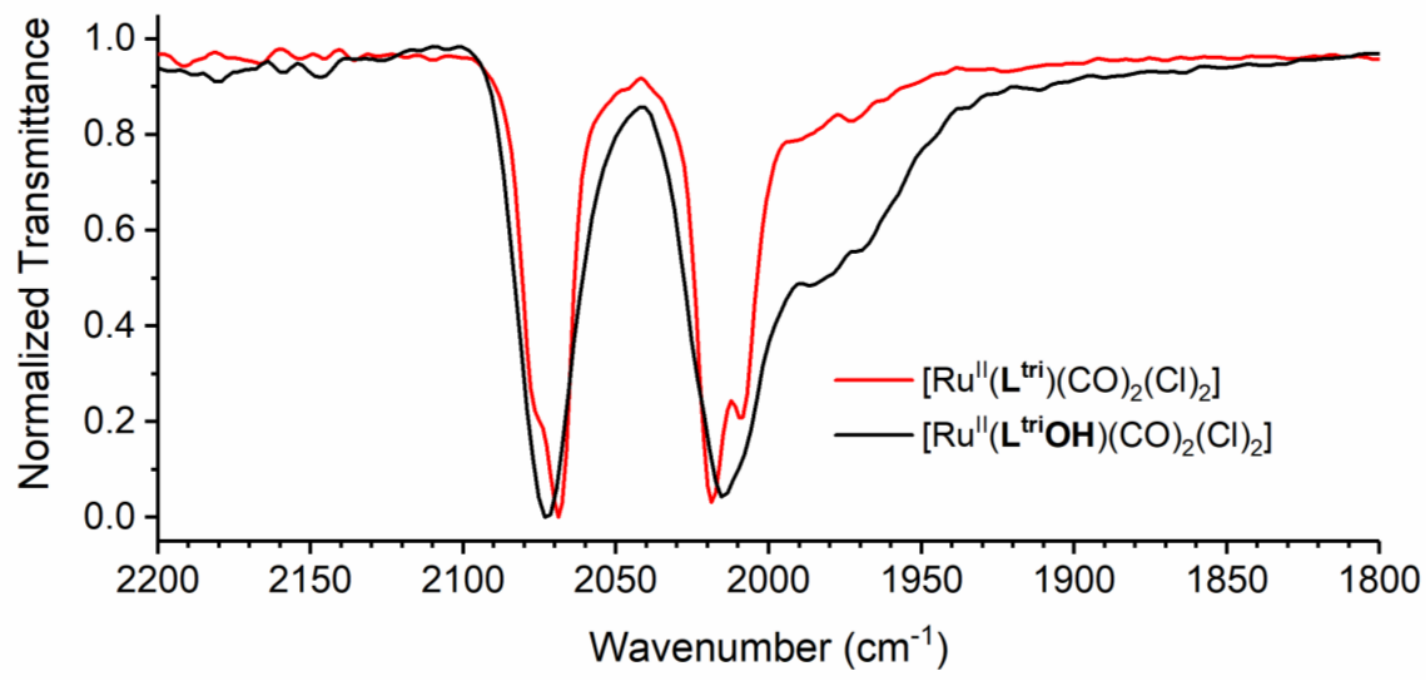

Figure S44. Comparison of the CO stretching bands in the ATR-IR spectrum of $\left[R u^{\prime \prime}\left(\mathbf{L}^{\text {tri }}\right)(\mathrm{CO})_{2} \mathrm{Cl}_{2}\right]$ and $\left[\mathrm{Ru}^{\prime \prime}\left(\mathrm{L}^{\text {triOH }} \mathrm{OH}\right)(\mathrm{CO})_{2} \mathrm{Cl} \mathrm{I}_{2}\right]$. 


\section{Antimicrobial Activity}

Table S6. Minimum inhibitory concentration of all compounds tested against a range of gram positive and gram negative bacteria.

\begin{tabular}{|c|c|c|c|c|c|c|}
\hline \multirow[b]{3}{*}{ compound } & \multicolumn{6}{|c|}{ Minimal Inhibitory Concentration } \\
\hline & \multicolumn{3}{|c|}{ gram - } & \multicolumn{3}{|c|}{ gram + } \\
\hline & $\begin{array}{l}\text { E. coli DSM } \\
30083\end{array}$ & $\begin{array}{c}\text { A. baumannii } \\
\text { DSM } 30007\end{array}$ & $\begin{array}{l}\text { P. aeruginosa } \\
\text { DSM } 50071\end{array}$ & $\begin{array}{c}\text { B. subtilis } 168 \\
\text { DSM402 }\end{array}$ & $\begin{array}{l}\text { S. aureus } \\
\text { DSM } 20231\end{array}$ & $\begin{array}{c}\text { S. aureus } \\
\text { ATCC } 43300\end{array}$ \\
\hline Sulfamethoxazole & $>512 \mu \mathrm{g} / \mathrm{mL}$ & $>512 \mu \mathrm{g} / \mathrm{mL}$ & $512 \mu \mathrm{g} / \mathrm{mL}$ & $>512 \mu \mathrm{g} / \mathrm{mL}$ & $>512 \mu \mathrm{g} / \mathrm{mL}$ & $>512 \mu \mathrm{g} / \mathrm{mL}$ \\
\hline Trimethoprim & $1 \mu \mathrm{g} / \mathrm{mL}$ & $128 \mu \mathrm{g} / \mathrm{mL}$ & $>512 \mu \mathrm{g} / \mathrm{mL}$ & $1 \mu \mathrm{g} / \mathrm{mL}$ & $8 \mu \mathrm{g} / \mathrm{mL}$ & $>512 \mu \mathrm{g} / \mathrm{mL}$ \\
\hline Co-trimoxazole & $8 \mu \mathrm{g} / \mathrm{mL}$ & $>512 \mu \mathrm{g} / \mathrm{mL}$ & $512 \mu \mathrm{g} / \mathrm{mL}$ & $4 \mu \mathrm{g} / \mathrm{mL}$ & $16 \mu \mathrm{g} / \mathrm{mL}$ & $>512 \mu \mathrm{g} / \mathrm{mL}$ \\
\hline$\left[\operatorname{Re}^{\prime}\left(\mathrm{Ltri}^{\mathrm{tr}}\right)(\mathrm{CO})_{3} \mathrm{Cl}\right]$ & $>512 \mu \mathrm{g} / \mathrm{mL}$ & $>512 \mu \mathrm{g} / \mathrm{mL}$ & $>512 \mu \mathrm{g} / \mathrm{mL}$ & $>512 \mu \mathrm{g} / \mathrm{mL}$ & $256 \mu \mathrm{g} / \mathrm{mL}$ & $256 \mu \mathrm{g} / \mathrm{mL}$ \\
\hline$\left[\operatorname{Re}^{\prime}\left(\mathrm{Ltri}^{\mathrm{tr}}\right)(\mathrm{CO})_{3} \mathrm{Br}\right]$ & $>512 \mu \mathrm{g} / \mathrm{mL}$ & $>512 \mu \mathrm{g} / \mathrm{mL}$ & $>512 \mu \mathrm{g} / \mathrm{mL}$ & $>512 \mu \mathrm{g} / \mathrm{mL}$ & $256 \mu \mathrm{g} / \mathrm{mL}$ & $512 \mu \mathrm{g} / \mathrm{mL}$ \\
\hline$\left[\mathrm{Ru}^{\prime \prime}\left(\mathrm{L}^{\mathrm{tri}}\right)(\mathrm{CO})_{2} \mathrm{Cl}_{2}\right]$ & $>512 \mu \mathrm{g} / \mathrm{mL}$ & $>512 \mu \mathrm{g} / \mathrm{mL}$ & $>512 \mu \mathrm{g} / \mathrm{mL}$ & $>512 \mu \mathrm{g} / \mathrm{mL}$ & $>512 \mu \mathrm{g} / \mathrm{mL}$ & $>512 \mu \mathrm{g} / \mathrm{mL}$ \\
\hline$\left[\operatorname{Re}^{\prime}\left(\mathrm{L}^{\text {tri }} \mathrm{OH}\right)(\mathrm{CO})_{3} \mathrm{Cl}\right]$ & $>512 \mu \mathrm{g} / \mathrm{mL}$ & $>512 \mu \mathrm{g} / \mathrm{mL}$ & $>512 \mu \mathrm{g} / \mathrm{mL}$ & $>512 \mu \mathrm{g} / \mathrm{mL}$ & $256 \mu \mathrm{g} / \mathrm{mL}$ & $256 \mu \mathrm{g} / \mathrm{mL}$ \\
\hline$\left[\operatorname{Re}^{\prime}\left(\mathrm{L}^{\text {tri OH }}\right)(\mathrm{CO})_{3} \mathrm{Br}\right]$ & $>512 \mu \mathrm{g} / \mathrm{mL}$ & $>512 \mu \mathrm{g} / \mathrm{mL}$ & $>512 \mu \mathrm{g} / \mathrm{mL}$ & $>512 \mu \mathrm{g} / \mathrm{mL}$ & $>512 \mu \mathrm{g} / \mathrm{mL}$ & $>512 \mu \mathrm{g} / \mathrm{mL}$ \\
\hline$\left[\mathrm{Ru}^{\prime \prime}\left(\mathrm{L}^{\text {triOH}}\right)(\mathrm{CO})_{2} \mathrm{Cl}_{2}\right]$ & $>512 \mu \mathrm{g} / \mathrm{mL}$ & $>512 \mu \mathrm{g} / \mathrm{mL}$ & $>512 \mu \mathrm{g} / \mathrm{mL}$ & $>512 \mu \mathrm{g} / \mathrm{mL}$ & $>512 \mu \mathrm{g} / \mathrm{mL}$ & $>512 \mu \mathrm{g} / \mathrm{mL}$ \\
\hline
\end{tabular}

\section{References}

1. CrysAlisPro, Agilent Technologies Yarnton, Oxfordshire.

2. Sheldrick, G., A short history of SHELX. Acta Crystallographica Section A 2008, 64 (1), 112-122.

3. Sheldrick, G., Crystal structure refinement with SHELXL. Acta Crystallographica Section C 2015, 71 (1), 3-8.

4. Dolomanov, O. V.; Bourhis, L. J.; Gildea, R. J.; Howard, J. A. K.; Puschmann, H., OLEX2: a complete structure solution, refinement and analysis program. J. Appl. Crystallogr. 2009, 42 (2), 339-341.

5. Albada, H. B.; Chiriac, A.-I.; Wenzel, M.; Penkova, M.; Bandow, J. E.; Sahl, H.-G.; Metzler-Nolte, N., Modulating the activity of short arginine-tryptophan containing antibacterial peptides with $\mathrm{N}$-terminal metallocenoyl groups. Beilstein J. Org. Chem. 2012, 8, 1753-1764. 